Esta revista forma parte del acervo de la Biblioteca Jurídica Virtual del Instituto de Investigaciones Jurídicas de la UNAM http://www.juridicas.unam.mx

https://biblio.juridicas.unam.mx

https://revistas.juridicas.unam.mx

DOI: http://dx.doi.org/10.22201/iij.24484881e.2020.43.15194

COMENTARIOS

LEGISLATIVOS

Universidad Nacional Autónoma de México, IIJ-BJV, 2020

https://revistas.juridicas.unam.mx/index.php/cuestiones-constitucionales/issue/archive 


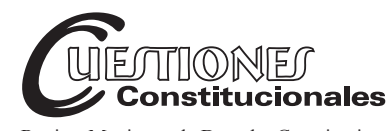

Revista Mexicana de Derecho Constitucional Núm. 43, julio-diciembre 2020

\title{
La falta de garantía de los derechos sexuales en Colombia: ¿cuestión de ineficacia normativa?*
}

\section{The lack of guarantee of sexual rights in Colombia: a matter of normative inefficiency?}

\author{
Alirio Jesús AlZATE JARAMILLO** \\ Carlos Alberto MoJICA ARAQUE***
}

RESUMEN: De los derechos humanos sexuales se reclama constantemente una protección eficaz por parte del poder estatal para poder así verificar una verdadera legitimación de los contenidos constitucionales y legales que se erigen para este propósito. Este artículo analiza las diferentes prescripciones normativas enunciadas a través de la dogmática constitucional y penal, nacional e internacional, que se encauzan para proteger estos derechos, y en donde las diferentes concepciones sobre aquéllos encuentran sin duda una validez en su construcción a partir del concepto de la dignidad humana.
ABSTRACT: Sexual human rights are constantly demanding effective protection by the state power in order to verify a true legitimization of the constitutional and legal contents that are erected for this purpose. This article analyzes the different normative prescriptions enunciated through the constitutional and criminal dogmatic, national and international, that are channeled to protect these rights and where the different conceptions about those find no doubt a validity in their construction from the concept of human dignity.

* El presente artículo es un avance del trabajo de investigación titulado "El delito sexual en Colombia. Un análisis de la afectación en los derechos humanos, de su investigación y juzgamiento" adelantado dentro del programa del doctorado en Derecho de la Universidad de Medellín, en el cual los autores son el estudiante y el asesor temático y metodológico, respectivamente.

** Doctorando en Derecho, magíster en Derecho, especialista en Derecho Probatorio Penal, abogado, experto en Investigación Criminal, y actualmente vinculado con la Procuraduría General de la Nación, Colombia. Colombia. ORCID: 0000-0003-2099-4551. Correo electrónico: aliriojalzate@yahoo.es.

*** Doctor en Derecho, magíster en Relaciones Internacionales (España), magíster en Derecho Procesal, especialista en derecho penal, abogado y profesor del área penal y procesal penal de la Universidad de Medellín, Colombia. Colombia. ORCID: J -3795-2016. Correo electrónico: camojica@udem.edu.co. 
Un análisis crítico de esas normas nos permite constatar en principio lo frágil que resultan el poder y la fuerza del Estado para garantizar estos derechos, cuando desde la misma dialéctica es posible construir también un discurso de ineficacia de aquellas normas. No obstante, aquel calificativo verificado de alguna manera en la praxis parece seguir siendo el resultado de la histórica y poco cambiante conducta irracional de sus destinatarios, lo cual impide consolidar una verdadera barrera frente a la eventual trasgresión. Cuando se supere dicha irracionalidad, será entonces posible constatar lo que teleológicamente anhela el Estado a través del derecho y el poder, que entre otros fines está el respeto por los derechos sexuales ajenos.

Palabras clave: protección, derechos sexuales, eficacia normativa, dogmática, poder, dialéctica, axiología.
A critical analysis of these norms allows us to verify in principle how fragile the power and strength of the State are to guarantee these rights, when from the same dialectic it is also possible to construct a discourse of inefficiency of those norms. However, that qualifier verified in some way in the practice seems to remain the result of the historical and unchanging behavior of its recipients; which prevents consolidating a true barrier against eventual transgression. When this irrationality is overcome, it will then be possible to verify what the State longs for teleologically through Law and power, which, among other purposes, is respect for the sexual rights of others.

Keywords: protection, sexual rights, normative efficacy, dogmatics, power, dialectics, axiology.

\begin{abstract}
SUMARIO: I. Introducción. II. Los derechos humanos sexuales y su olvidada delimitación filosófica. III. Instrumentos jurídicos de protección internacional y nacional de los derechos sexuales: una mirada desde la dogmática constitucional y penal en Colombia. IV. Una revisión al dogma de la garantía de los derechos sexuales. V. Conclusiones. VI. Bibliografía.
\end{abstract}

\title{
I. INTRODUCCIÓN
}

Para las personas, la libertad, la integridad y la formación sexual son derechos humanos de muy alto raigambre que siempre han sido vistos como esa gran posibilidad de disfrute y desarrollo integral del individuo por cuanto maximizan su dignidad humana. Esto, por sí mismo, pone de presente la necesidad de que dichos derechos sean respetados por los integrantes de la sociedad y, en estricto sentido, garantizados por el Estado a través de su ordenamiento jurídico, bajo la más alta aspiración de que no serán vulnerados por ningún motivo. No obstante, como fenómeno criminal y lastimosamente siempre constatado desde los albores de la humanidad, encontramos el delito sexual como un acto que irrumpe profundamente aquella

Esta obra está bajo una Licencia Creative Commons

Atribución-NoComercial-SinDerivar 4.0 Internacional, IIJ-UNAM. 
dignidad humana, y que cada vez más aflige a las personas sin distinción alguna, lo cual deja en sí misma un desalentador y conclusivo panorama que comúnmente denominamos ineficacia normativa, por cuanto pone en cuestión los fines y la filosofía de protección en la cual se fundamenta nuestro Estado social de derecho a través de las normas existentes.

Es por esta compleja paradoja por lo que surge la constante reflexión, pero ahora bajo una seria consideración sobre aquel ser - el hombre-que se presenta como un constante agresor de estos derechos, y que pareciera actuar desde lo más retrógrado de su instinto primitivo de naturaleza humana, poniendo en constante y grave riesgo cualquier intento dogmático de protección y de autoridad estatal en ese sentido, pues con su conducta parece no temerle al poder punitivo del Estado.

En ese orden, llama la atención todo lo concerniente a la obligación que Colombia se trazó desde aquella apuesta de propender por un modelo de Estado social y democrático de derecho, en donde sus instituciones públicas y todos los integrantes de la sociedad quieren ver garantizados sus derechos y libertades, ${ }^{1}$ y de esa forma permitir que impere siempre la legitimación del poder expresado en sus normas jurídicas, finalidad que se traduce cuando se otorgan y se limitan los derechos, entre ellos los de orden sexual; normas que necesariamente también resultan ser de tipo prohibitivo, y que históricamente se apuntalan desde la dogmática penal, en razón de que los límites constitucionales no parecen ser asimilados por el mismo hombre.

A su turno, resulta también obligado aproximarnos a la reflexión sobre la conceptualización de los derechos sexuales a la luz de los derechos humanos y su aspecto natural y normativo, teniendo en cuenta las diferentes clasificaciones que la doctrina viene encauzando sobre esta gama de derechos, desde donde tendremos que sostener que los derechos de índole sexual, que vienen de ser sumamente importantes, porque le dan el cimiento al resto de las dimensiones del ser humano, han de ser de especial interés, y exigen en la actualidad una amplia y constante protección eficaz del Estado.

Bajo este panorama, resultará necesaria la mención precisa y clara sobre la respuesta que jurídicamente el Estado colombiano ha brindado a nivel internacional con miras a cumplir ese encargo de protección y garantía ante cualquier posibilidad de vulneración, lo que para muchos se

1 Molina Betancur, Carlos Mario, Investigación: bicentenario constitucional, Medellín, editorial U de M. 2010, pp. 1-10. 
puede traducir en la actualidad en un cumplimiento formal de ese compromiso supraestatal, porque se refleja a la vez, y paralelamente latente, ese grave incumplimiento a nivel interno a la hora de pretender materializar y garantizar dicha protección. A partir de lo anterior, surge la siguiente situación problemática como una de las aristas que se viene abordando en esta investigación, y que para este trabajo se puede plantear de la siguiente manera: ¿resulta acertado calificar como ineficaz a la Constitución y a la ley por cuanto en la praxis se constata la vulneración de los derechos sexuales de la sociedad? Para acercarnos a una respuesta objetiva de este aspecto, resulta inescindible tratar de conciliar desde la dialéctica, y de manera inicial brindar una posible respuesta a los siguientes interrogantes: ¿qué se debe entender por "eficacia normativa"? ¿Es posible hablar también de una fractura axiológica y sociológica como punto de partida para la trasgresión de los derechos sexuales en la sociedad?

Son estas cuestiones, y sin duda que sobre esta materia existen muchas más, las que motivan estas reflexiones sobre las posturas dogmáticas y filosóficas de protección de los derechos sexuales en Colombia, y nos permiten fundamentar el análisis de una forma objetiva y serena, identificando si nuestra dogmática jurídica constitucional descansa realmente en nuestra sociedad cumpliendo aquel principio de efecto útil para el cual fueron creadas; es decir, materializando esa verdadera concepción finalista que se debe traducir en eficacia normativa; o si, por el contrario, cobran sentido las buenas razones que en gran parte de la sociedad se instalan, cuando sostienen que dicho orden jurídico sólo presenta rasgos de ineficacia al no poder garantizar estos derechos sexuales, y mucho menos desde la norma penal, que tampoco logra disuadir al individuo en su no afectación en todo tiempo y lugar. Lo anterior, nos permitirá considerar seriamente, si de manera silente pueden estar coexistiendo entre estas dos máximas alguna postura intermedia, que extrañamente se ha visto diluyendo con el tiempo, y a la cual se le resta importancia; hablamos de aquella en donde se ubica necesariamente el hombre como el único responsable de este estado de cosas normativamente ineficaces, en el sentido de que a partir de su irracionalidad e inmadurez social viene despreciando no sólo las normas jurídicas, sino también la libertad y la integridad sexual de su congénere, como si aún permaneciera inmerso en un estado de naturaleza humana, lo que termina desdibujando los contenidos axiológicos y sociológicos del mismo sistema normativo. 
Para entender el poder político correctamente, y para deducirlo de lo que fue su origen, hemos de considerar cuál es el estado en que los hombres se hallan por naturaleza. Y es éste un estado de perfecta libertad para que cada uno ordene sus acciones y disponga de posesiones y personas como juzgue oportuno, dentro de los límites de la ley de naturaleza, sin pedir permiso ni depender de la voluntad de ningún otro hombre. ${ }^{2}$

Si cobra sentido la premisa anterior, puede resultar prudente no seguir cuestionando las normas jurídicas por no haber alcanzado el objetivo que algunos teóricos del derecho le han asignado en vieja data, que entre otros es el de generar orden social y regular la conducta humana para poder vivir armónicamente. Lo anterior, habrá de superarse teniendo en cuenta que ni el derecho de las primeras civilizaciones ni mucho menos el moderno o al que muchos llaman postmoderno, han podido lograr dicho propósito en todo su esplendor.

A partir de esta postura filosófica, sería entonces también loable que ese cuestionamiento de ineficacia también lo soporten otras ciencias o disciplinas sociales que se deben al hombre en todas sus dimensiones; es decir, por no haber alcanzado tampoco una última conclusión sobre la correcta conducta en sociedad; claro está, sin pretender descalificar lo que las normas jurídicas han logrado frente al hombre a través los tiempos, pero en su justa proporción. En otras palabras, se quiere poner de relieve que la presunta ineficacia de esas normas jurídicas se puede estar presentando aún, porque más allá de la obediencia y compresión del hombre sobre una concepción o prescripción jurídica, éste elige muchas veces obedecer primero a su estructura natural, claramente irracional, cuando irrumpe en los derechos sexuales del otro, sin dimensionar sus resultados. Esta libertad, humana anteriormente descrita, también ha puesto en constante cuestión los propósitos de otras ciencias sociales que abordan el objeto de conocimiento desde el paradigma positivista, que viene de superar otros estados teóricos del conocimiento, ${ }^{3}$ pretendiendo construir una sociedad y un derecho desde la vida, con todo lo que ello implica, y no desde los textos, como regularmente pasa.

2 Locke, John, Segundo tratado sobre el gobierno civil, trad. española de Carlos Mellizo, Madrid, Alianza Editorial, 1998, p. 36.

3 Comte, Augusto, Primeros ensayos, trad. de Francisco Giner de los Ríos, México, Fondo de Cultura Económica, 1942, p. 107. 
Por lo tanto, para el desarrollo de este artículo se adoptará una metodología descriptiva analítica, que se presentará en dos partes: la primera, se centrará en la fundamentación filosófica de los derechos humanos, en este caso los de índole sexual, y analizando los elementos de fuerza y de poder con los que cuenta el Estado para lograr su verdadera garantía y eficacia en la protección; luego, descenderemos a su conceptualización, la que, sin duda, nos permitirá otros análisis a partir de las marcadas clasificaciones que la misma ley trae consigo dependiendo el tipo de víctimas de agresión sexual y el contexto donde ocurran las mismas; en la segunda parte de este artículo se pondrá en escena todo el orden normativo internacional y nacional que el Estado colombiano ha venido adoptando a partir de ese intento dogmático de protección de los derechos sexuales en la sociedad colombiana, lo que nos permitirá acercarnos a la respuesta de aquellos interrogantes que surgen en esta investigación sociojurídica, y a partir de allí, poder plantear algunas ideas que nos permitan hablar de la eficacia normativa para la protección de los derechos sexuales, desde una postura teórica, que permita rescatar la inescindible relación que debe existir entre el derecho con las demás ciencias sociales que se involucran con el hombre y, por supuesto, con la axiología; por último, se precisarán las conclusiones y las referencias bibliográficas.

\section{LOS DERECHOS HUMANOS SEXUALES Y SU OLVIDADA DELIMITACIÓN FILOSÓFICA}

Una de las principales razones frente a la constante reclamación del respeto por los derechos humanos surge de considerar que los mismos son originarios de un estado de naturaleza, ${ }^{4}$ que trasciende en el derecho natural. Encontramos que este reclamo parece surgir del malestar que se siente cuando encuentran regulada su conducta por un poder y una autoridad que pugna muchas veces con los lineamientos de algún contrato social

\footnotetext{
4 Bobbio, Norberto, Sociedad y Estado en la filosofía politica moderna. El modelo iusnaturalista y el modelo hegeliano-marxiano, México, Fondo de Cultura Económica, 1997, p. 79. Según el autor, la posición de Rousseau era compleja, porque la concepción de la humanidad y su desarrollo no era dual — estado de naturaleza o sociedad civil-, donde el primer momento es negativo, y el segundo, positivo. La teoría de Rousseau es que ha sido tríadica - estado de naturaleza, sociedad civil, república (fundada en el contrato social) - donde el momento negativo, que es el segundo, es puesto entre dos momentos positivos.
} 
ficticio, ${ }^{5}$ al cual se vieron avocados históricamente por aquella necesidad de constituirse como Estado, pues recuérdese que allí se materializaría la idea de una sociedad políticamente organizada.

No obstante, esa reclamación puede ser entendida también como aquella intención de no seguir compartiendo tal relación contractual, dado que la misma implicó desde siempre unas enormes limitaciones en el disfrute de los derechos a partir de las cláusulas que esos cuerpos normativos establecieron, con la finalidad de hallar un equilibrio en la convivencia armónica de la sociedad, es decir, el orden.

Sostener lo anterior conduce a que cobre sentido que ese estado de naturaleza fuera interpretado disyuntivamente a partir de dos posibilidades de asociación política que marcaron ese camino al menos en los albores del siglo XVII: i) un absolutismo que propendía la concentración del poder para el manejo y la restricción de la libertad y la igualdad del individuo dada la desconfianza misma entre aquéllos; recordemos que esa teoría radica en Thomas Hobbes, ${ }^{6}$ y ii) bajo el pensamiento de John Locke, ${ }^{7}$ cuando señalaba que era posible la asociación civil y política entre los hombres y el ejercicio del poder, a partir del reconocimiento y respeto por las leyes y de las propias libertades humanas, lo cual sería posible a través de la razón.

Desde estos ángulos filosóficos, la primera postura se justificaba históricamente, porque era el mismo hombre y sus pasiones los que desenca-

5 Ibidem. pp. $47-122$.

6 Hobbes, Thomas, Leviatán, trad. de M. Sánchez Sarto, México, Fondo de Cultura Económica, 1980, p. 265.

7 “...Así, cuando un grupo de hombres ha consentido formar una comunidad o gobierno, quedan con ellos incorporados a un cuerpo político en el que la mayoría tienen el derecho de actuar y decidir en nombre de todos. Pues cuando un número cualquiera de hombres, con el consentimiento de cada individuo, ha formado una comunidad, ha hecho de esa comunidad un cuerpo con poder de actuar corporativamente; lo cual sólo se consigue mediante la voluntad y determinación de la mayoría. Porque como lo que hace actuar a una comunidad es únicamente el consentimiento de los individuos que hay en ella, y es necesario que todo cuerpo se mueva en una sola dirección, resulta imperativo que el cuerpo se mueva hacia donde lo lleve la fuerza mayor, es decir, el consenso de la mayoría. De no ser así, resultaría imposible que actuara o que continuase siendo un cuerpo, una comunidad, tal y como el consentimiento de cada individuo que se unió a ella acordó que debía ser. Y así, cada uno está obligado, por consentimiento, a someterse al parecer de la mayoría. Vemos, por lo tanto, que en aquellas asambleas a las que se ha dado el poder de actuar por leyes positivas, cuando un número fijo no ha sido estipulado por la ley que les da el poder, el acto de la mayoría se toma como acto del pleno; y, desde luego, tiene capacitad decisoria, pues tiene el poder del pleno, tanto por ley de naturaleza como por ley de razón”. Locke, John, Segundo tratado sobre el gobierno civil, cit., pp. 111 y 112. 
denaban un estado natural de violencia, sin poder hallar en sí mismos una voluntad de reflexión interna y de respeto frente a los otros. En ese sentido, surgía la idea de que dos libertades eran incompatibles entre sí; es decir, los hombres libres y el poder, pues sólo una estaba llamada a prosperar, y para aquella época lo era aquella que representaba el poder. Lo anterior, teniendo en cuenta, además, que ese poder tenía la posibilidad de mantener vigilado el ejercicio de la libertad y los demás derechos de las personas, que en últimas siempre fueron vistos como fuente de pasiones y sin freno alguno, por lo que también estas posturas se asociaban claramente a un egoísmo racional.

Si echamos un vistazo al ángulo filosófico de Locke, se observa como más benevolente con el hombre y su estado mismo de naturaleza humana, al considerarlo con "moral y razón", bajo la idea que éste era capaz de controlar sus propios excesos acudiendo a la prudencia. ${ }^{8}$ Entre tanto, vistos así estos argumentos, implican la coexistencia de dos posturas dialécticamente opuestas: la primera, es la que se estructura en esa petición de libertad para algo que quiere y necesita el hombre, pero que raya cuando esa libertad resultaba siendo exigida posteriormente para otras cosas, y es allí en donde Hobbes justifica la idea de que el hombre debe renunciar a todo, pues de entregarse al hombre dicha libertad en ese todo, ese todo lo mantendría en un constante estado de guerra. Sin embargo, la segunda postura indica que se puede renunciar a algo porque la razón y la prudencia es la que pone límites a esa la libertad, así como lo expresó Locke.

Pero hay otro pensamiento que ahonda aún más en este aspecto. Nos referimos al de Norberto Bobbio, cuando refiriéndose al tema de las obligaciones en correspondencia con la ley, afirma que "...la función primaria de la ley no es liberar, sino oprimir, no ampliar los espacios de libertad

8 “Así, la libertad de un hombre, y la de actuar de acuerdo con su propia voluntad, se fundamenta en que dicho hombre posee una razón que lo capacita para instruirlo en las leyes por las que ha de regirse y para poner en su conocimiento los límites de su voluntad libre. Dejarlo a rienda suelta, sin cortapisa alguna a su libertad, antes de que posea esa razón que puede guiarlo, no es concederle su privilegio natural de ser libre, sino arrojarlo entre las bestias y abandonarlo a un estado tan miserable y tan inferior al hombre como el de aquellas. Esto es lo que pone en manos de los padres la autoridad de gobernar a sus hijos mientras éstos son menores de edad. Dios ha encargado a los padres que cuiden de su descendencia, y ha puesto en ellos las apropiadas inclinaciones de ternura y cuidado para que regulen este poder y para que lo apliquen, según fue designado por la sabiduría divina, al bien de los hijos mientras éstos necesitan estar bajo su tutela". Locke, John, Segundo tratado sobre el gobierno civil, cit., p. 84. 
sino restringir y no dejar crecer el árbol salvaje, sino enderezarlo cuando se tuerce". ${ }^{9}$

Alrededor de estos postulados, podemos inferir prudentemente que nuestra sociedad actual se encuentra aún en un punto medio o gris; es decir, como súbditos y hombres libres, y lo anterior es plausible si se propende mantener un orden. Y es que esta expresión social y política se verifica así, por cuanto debemos tener en cuenta que el poder que brinda la ley para gobernar a los pueblos, en cualquier modelo de Estado y sistema de gobierno posible, se encuentra muchas veces permeado de despotismo cuando se utiliza la ley y el poder para maltratar la libertad de los hombres. Por consiguiente, si se presenta tal proceder, su consecuencia más probable es la constante deslegitimación de ese poder; esta idea termina contrariando ese ideal común al cual se decidió apostarle a partir de ese modelo de sociedad políticamente organizada. En otras palabras, el primario estado de naturaleza humana esperaría así una posible coexistencia armónica entre sociedad y poder, para mantener estable lo que surge de estos dos, que es claramente un Estado con normas y una autoridad que obligan, incluso, bajo amenazas de sanción.

Ahora bien, estos elementos verificados en contexto nos permiten afirmar que quienes deciden vivir en sociedad deben comprender que todos sus derechos y libertades serán regulados por la ley, incluso aun si se predicara del individuo un cierto grado de anarquía.

No se puede perder de vista que aquel fundamento filosófico ha sido una de las grandes justificaciones a través de la historia para que derechos tan caros como la libertad, la integridad y la formación sexual sean protegidos por los Estados con normas jurídicas que buscan disuadir de manera efectiva la conducta anómala de algunos individuos. Todo lo anterior, claro está, para lograr una actitud de respeto y no afectación en el otro bajo el marco de un modelo de Estado social y democrático de derecho, que se propone como máximo pilar el disfrute de los derechos y libertades para la efectiva realización de todos los individuos.

Entre tanto, vemos claramente, y así se puede verificar en el Estado colombiano, que la ley no viene siendo un presupuesto de garantía efectiva para el goce de esos derechos sexuales, pues habrá de tenerse en cuenta que no es ella en sí misma la que garantiza el respeto por aquellos derechos, sino que ha de ser la razón y la reflexión interna del sujeto las que

9 Bobbio, Norberto, El tercero ausente, Madrid, Cátedra, 1997, p. 163. 
tienen que verse reflejadas desde su correcto proceder, es decir, sin perder de vista el constante límite de su libertad que le marca aquella ley y acompañándolo necesariamente de un cierto grado de moralidad.

Al llegar a este punto, resulta obligado considerar aquel afán de muchas personas que resultan afectadas en sus derechos sexuales, cuando naturalmente buscan una respuesta del Estado a partir de esa gama jurídica de protección que quedó establecida en nuestra Constitución política. Después de todo, no parece fortuito entonces que la misma conducta dañina de aquellos hombres, los que aún se mantienen en el retrógrado estado de naturaleza, que no aceptan ni siquiera un mínimo de civilización humana para coexistir armónicamente y con el suficiente respeto hacia los derechos sexuales ajenos, sean los que en últimas pongan en entredicho aquellas doctrinas contractualistas antes enunciadas, por aquello de que el hombre parece no ser capaz de ser libre y estar sometido a la ley al mismo tiempo.

Por consiguiente, se puede en principio sostener serenamente que se hace impensable un Estado en el cual se pretenda que los hombres guarden un equilibrio entre sus pasiones y la razón, pues exigir un propósito como estos implica desconocer la forma natural de la evolución humana, que viene de ser producto de la inicial irracionalidad y desconfianza entre los mismos seres humanos, y que en la actualidad parece no haberse superado totalmente como producto de su egoísmo innato; claro está, se parte de hechos empíricamente constatables en este sentido.

De este modo, el anhelo social de respeto por los derechos sexuales ajenos no recomienda esgrimir argumentos que puedan poner en tensión dialéctica toda una historia llena de teorías filosóficas en constante evolución; por ejemplo, las del iusnaturalismo y el iuspositivismo en materia de origen y concepción de los derechos humanos, pero paradójicamente no replanteadas o destruidas por el tiempo presente; sin dejar de considerar que existen problemas mayores que el derecho actual debe resolver, y por eso no debe quedarse estancado en esas disquisiciones filosóficas e intelectuales. En ese sentido, no resulta ser menos cierto que al fallar el hombre en algo tan natural como lo es la autorregulación de su desbordada lividez, lo conduce también a desestimar al semejante en sus derechos sexuales y, de paso, desprecia la Constitución y las leyes del Estado, que vienen de ser producto de esa presunta racionalidad. En otras palabras, al no escaparse ese sistema jurídico ${ }^{10}$ de ser irrespetado por las propias pasiones

10 Kelsen, Hans, Teoría pura del derecho, México, UNAM, 2002, p. 45. 
y apetitos de sus destinatarios, estas prescripciones normativas en últimas se pueden traducir en un discurso falaz sobre aquel intento dogmático de protección, porque ni las normas jurídicas ni la autoridad o el poder que ellas entregan a los gobernantes logran cumplir con el propósito para el cual fueron creadas.

\section{El poder y la fuerza del Estado como débiles elementos para la garantía de los derechos sexuales}

Es cierto que en la contemporaneidad, Colombia, como Estado social y democráticamente constituido, supone la inexistencia de la fuerza, por cuanto de manera pacífica su sociedad ya viene eligiendo quién y de qué manera deberá gobernar su territorio; es decir, podemos sostener que estamos bajo un modelo de democracia legítima, donde se respetan los derechos fundamentales; ${ }^{11}$ o también, en donde se incluyen a todos los integrantes de la sociedad en una idea de razón pública en la cual también se respetan los principios de justicia. ${ }^{12}$

Lo anterior significa que cuando se delega el poder, ese delegatario debe disponer de una manera recta y eficaz todo su actuar para seguir construyendo, políticamente hablando, una sociedad armónica y en convivencia. A partir de allí, se puede sostener una legitimación en su ejercicio, ya sea de manera tácita o expresa por parte de sus destinatarios, en los cuales recaen las decisiones gubernamentales. Sin embargo, sin dejar de aplaudir aquellos avances, no es menos cierto y se hace necesario recordar, que estos Estados democráticos no surgen de una sola idea política o filosófica, como tampoco de un marco axiológico preestablecido, y mucho menos de la aceptación pacífica de las normas que se estructuran en su interior; por el contrario, son producto de toda una evolución histórica, que en su mayoría de veces se ha visto permeada por el uso de la fuerza de quien pretende ejercer el poder en virtud de un apetecido y prolongado gobierno, que como fenómeno humano constante se expresa al interior de los Estados. ${ }^{13}$

\footnotetext{
11 Kelsen, Hans, Esencia y valor de la democracia, Buenos Aires, Labor, 1984, p. 14.

12 Rawls, John, Liberalismo político, Barcelona, Crítica, 2002, p. 266.

13 "Para la generalidad de estas doctrinas, el Estado es la fuerza del poder político y ésta siempre se ha manifestado por medio de la imposición. La fuerza del Estado pertenece a aquel que se ha sabido imponer sobre los demás. Surgen estas teorías, como oposición a las teorías teológicas, dando preponderancia al poder de dominación o sujeción de las fuerzas sociales, frente a la sumisión a una voluntad divina. La sociología y la 
A primera vista, y considerando la idea anterior, desde esa fuerza para gobernar e imponer las leyes desde una expresión positivista, vemos que se observan formalmente los principios que rigen el modelo de Estado que tenemos, y sobre el cual se orienta a la promoción y garantía de los derechos humanos de índole sexual; no obstante, no debemos olvidar que dicha expresión de creación del derecho en aquellos términos puede eventualmente estar atendiendo una clara fundamentación teórica de las libertades fundamentales ${ }^{14}$ aunque no sea del todo pura. Lo anterior indica que el Estado, basado en sus principios fundamentales que le irradian constitucionalmente, presenta un constante desarrollo en pro de las exigencias internacionales, que invitan a la adquisición de obligaciones en esa materia; con esto permite dejar explícitas unas funciones de protección a partir de un orden supraconstitucional, que se fundamenta en los tratados y convenios internacionales de carácter regional. ${ }^{15}$

Sin embargo, en el Estado colombiano la atención y protección de los derechos sexuales queda adormecido, y ¿por qué no decirlo?, también sumamente descuidados por aquello que sus esfuerzos encuentran una obligada bifurcación por la exigencia social de luchar también internamente contra otros factores y actores generadores de violencia, como lo son el narcotráfico, la corrupción, los grupos de guerrilla, paramilitares, bandas criminales, entre otros, que demandan cada vez más la atención de la fuerza y el poder del Estado, incluso, a la luz de estar buscando salidas negociadas para la terminación del conflicto interno que entre éstos persiste, sin percatarse, en la mayoría de las veces, de que lo anterior resulta siendo un sofisma de distracción del cual se deriva que los delitos sexuales terminen

antropología han puesto en evidencia el poder de coerción que ejercen los hombres entre sí en todas las sociedades humanas, arcaicas o modernas. En realidad, no se concibe el Estado sin el poder que implica la existencia de una autoridad que puede ser opresiva o mesurada. Para poder ejercer esta fuerza se requiere de la coerción, de la presión violenta de la autoridad que necesita en ciertos casos la brutalidad". Molina Betancur, Carlos Mario et al., Derecho constitucional general, Medellín, Universidad de Medellín, 2008, pp. 99 y 100.

14 Fioravanti, Maurizio, Los derechos fundamentales. Apuntes de historia de las constituciones, Madrid, Trotta, 2007, pp. 25-53.

15 En especial, y para nuestra región, se establece en la Convención Americana de Derechos Humanos con su órgano de protección y jurisdicción como la Corte Interamericana de Derechos Humanos, y en otras latitudes, la Corte Europea de Derechos Humanos. Aguirre Arango, José Pedro, "La interpretación de la Convención Americana sobre Derechos Humanos”, Revista de Derechos Humanos, año V, núm. 8, 2007, pp. 73-97. 
siendo desdibujados en estos escenarios, tanto en su misma fundamentación y filosofía de protección como también en su juzgamiento y las garantías de reparación que en estos procesos se predican. ${ }^{16}$

Al llegar a este punto, no resulta ser tarea fácil identificar los argumentos políticos que amparan ese descuido público sobre la debida atención en esta materia, pues los innumerables discursos políticos a partir del ejercicio de poder del gobierno ${ }^{17}$ terminan reducidos a simples falacias, que paradójicamente le generan un blindaje sociopolítico a lo paquidérmico de las acciones positivas que se manifiestan desde el Estado. Por lo tanto, lo que no se explica claramente es cómo los gobernantes rinden informes ante la comunidad nacional e internacional pretendiendo reflejar el cumplimiento efectivo de las obligaciones adquiridas frente a estos derechos de índole sexual, y es bajo este escenario desde donde resulta simple distinguir que la letra formal, escrita con pluma diplomática, logra constantemente distraer la realidad aberrante que aqueja a la sociedad, que cada vez ve más distante ese marco de cumplimiento y garantía de una verdadera libertad, integridad y formación sexual de sus habitantes. Así lo expuso el profesor Carlos Gaviria Díaz al afirmar:

Esa concepción y ese logro que es el Estado de Derecho, sin embargo, ha sido sometido a muchas críticas. La primera de todas las libertades que se consagran, por ejemplo, en la declaración de los derechos del hombre y del ciudadano, son libertades eminentemente formales, lo que significa que se plasman en el papel, pero no garantizan que la persona pueda disfrutar de ellas en la realidad. En el manifiesto comunista de Marx y Engels en 1848 se plasma una crítica a ese tipo de libertades y, por tanto, al Estado Liberal

\footnotetext{
16 Véanse, por ejemplo, las leyes transicionales que ha adoptado Colombia en los últimos tiempos como lo es la Ley 975 de 2005, conocida como Ley de Justicia y Paz, que se expidió para que los grupos al margen de la ley se pudieran reincorporar a la sociedad y contribuyeran al logro de la paz, especialmente para la desmovilización de los denominados "paramilitares", pero donde también se beneficiaron integrantes de grupos guerrilleros. Asimismo, el Acto legislativo 01 de 2012 o Marco Jurídico para la Paz, que aprobó el Congreso de la República de Colombia a partir de las negociaciones de paz entre el gobierno y las Fuerzas Armadas Revolucionarias de Colombia "FARC" en La Habana, Cuba.

17 Van Dijk, Teun A., "Discurso, conocimiento, poder y política. Hacia un análisis crítico epistémico del discurso", Revista de Investigación Lingüistica, Murcia, vol. 13, 2010, pp. 167-215; véase también, Bozo de Carmona, Ana Julia, "Karl-Otto Apel: Reflexiones sobre la teoría de la verdad y la ética del discurso", Revista de Filosofía, Universidad de Zulia, núm. 22, julio-diciembre de 1995, pp. 103-119.
} 
o Estado de Derecho a secas, porque se considera que esas libertades así concebidas y así plasmadas son un engaño. ${ }^{18}$

Dentro de ese contexto, y aceptando a priori que en Colombia ya existe una normativa tendiente a garantizar el ejercicio de los derechos y libertades de orden sexual, surge objetivamente la tesis de que no resulta posible, al menos para este momento histórico, poder calificarlas de eficaces, por el hecho de estar allí inmersas en el cuerpo de la Constitución y desarrolladas ampliamente por el poder político en las leyes; ${ }^{19}$ sostener lo contrario, sería aprobar a la ligera el discurso ampliamente antropocéntrico que le sirvió de base para crear dichas normas; sin entrar a considerar los factores reales, es decir, los delitos sexuales propiamente dichos, que paulatinamente han venido entregado el insumo suficiente para la creación del derecho, pero que pasado el tiempo no ha sido capaz de conjurar.

Dicho en otros términos, la eficacia normativa se ha de constatar cuando con dicha creación jurídica se puede superar el fenómeno social que le dio origen; por ejemplo, evidenciando que día a día disminuyen los índices del delito; mas en este caso la realidad de este momento histórico no permite aprobar el argumento final de eficacia en la medida en que su verificación material no arroja los resultados esperados, ${ }^{20} \mathrm{y}$ en otro sentido, esa

18 Gaviria Díaz, Carlos, "Los temas de la constituyente. El Estado social de derecho y la presión política por el cambio", Revista de Derecho Foro, núm. 7, primer semestre 2007, p. 8.

19 "Falacia politicista y falacia garantista. Es relativamente fácil delinear un modelo garantista en abstracto y traducir sus principios en normas constitucionales dotadas de claridad y capaces de deslegitimar, con relativa certeza, las normas inferiores que se aparen de él. Más difícil es modelar las técnicas legislativas y judiciales adecuadas para asegurar efectividad a los principios constitucionales y a los derechos fundamentales consagrados por ellos. ... En este libro he desarrollado, prevalentemente, una crítica de la que llamaré falacia politicista: es decir, de la idea de que baste la fuerza de un poder bueno para satisfacer las funciones de tutela asignadas al derecho, antes aún, de que pueda existir un poder bueno, es decir, capaz de desempeñar tales cometidos sin la mediación de complejos sistemas normativos de garantías con capacidad de limitarlo, vincularlo, instrumentalizándolo y, de ser necesario, deslegitimarlo y neutralizarlo. Junto a la falacia politicista, puede sin embargo cultivarse también una falacia garantista: es decir, la idea de que basten las razones de un derecho bueno, dotado de sistemas avanzados y actuables de garantías constitucionales, para contener al poder y poner a los derechos fundamentales a salvo de sus desviaciones”. Ferrajoli, Luigi, Derecho y razón. Teoría del garantismo penal, Madrid, Trotta, 1995, pp. 940 y 941.

20 García Obando, Pedro Antonio y Aguirre Román, Javier Orlando, Lógica y teoría de la argumentación, Santander, Universidad Industrial de Santander, 2008, pp. 91-124. 
eficacia se evidenciará al momento de verificar si realmente se cumplen o no los presupuestos para los cuales fue creada la norma bajo tal estructura y propósito, es decir, para mantener incólume la integridad de la dignidad humana que se irradia a partir del goce efectivo de los derechos, ${ }^{21}$ en este caso, los sexuales.

Al evidenciar lo paradójico que resulta ser aquel ámbito dogmático sobre la protección de los derechos sexuales, seguido de su consecuente afectación, esta situación no brinda los elementos necesarios para entrar en comparaciones con respecto a cuál de las manifestaciones delictuales - acceso carnal violento, acto sexual abusivo, entre otros - genera mayor sufrimiento en las personas, pues a lo anterior se le puede restar importancia si lo que se pretende es poner de relieve el valor y la dimensión de aquellos derechos sexuales frente a la denominación lingüística en la tipificación del delito. Lo anterior, teniendo en cuenta que cualquier clasificación que eventualmente pueda darse sobre estos escenarios delictivos deberá pasar a un segundo plano, porque es un delito que toca al ser humano en su núcleo central de la dignidad, y, en clave de sus dimensiones, ninguna de éstas resulta ser más importante que otra, por cuanto de todas requieren su materialización; ergo, poder conservar su integralidad. A partir de lo anterior, surge como necesario que seguidamente se expongan algunos aspectos sobre lo que esto puede significar en la praxis.

\section{La (des)contextualización y (des)clasificación de los derechos sexuales}

Hablar de una posible clasificación de los delitos sexuales no implica necesariamente la categorización de los derechos afectados en ese núcleo esencial; es decir, que por el hecho de ser mínima la agresión sexual resulte posible pensar que se afecta entonces sólo un mínimo de dignidad humana. No obstante, en clave de la paradoja antes enunciada — protección-afectación - frente a la realización de las libertades y derechos sexuales de las personas, sí pareciera vislumbrarse esa especie de categorización o diferenciación, al menos en el contexto de un Estado social de derecho como Colombia. Lo anterior viene siendo explicado por la doctrina, que trata de enseñar que ésa resulta ser el método más indicado para una mejor asimila-

21 Alexy, Robert, El concepto y la validez del derecho, Barcelona, Gedisa, 2004, pp. 172-177. 
ción; es decir, pensarlo así terminaría siendo práctico para poder garantizar en alguna medida aquel núcleo de protección que predican las normas.

...Pero se mantiene, digamos, una categorización dentro de esa terminología, que yo llamaba un tanto desgastada de derechos de primera y segunda generación. Podemos decir que los derechos de primera generación tienen formas de protección más expeditas que los derechos de segunda generación o que las libertades que corresponden al primer paradigma de la dignidad humana, son más fácilmente protegibles que los derechos o la garantía de los derechos que corresponden a ese segundo paradigma de la dignidad humana, digamos las aspiraciones humanas, los deseos, las metas que se van transformando históricamente y por tanto, mirar los derechos de esa manera como correspondientes a distintas concepciones de la dignidad humana, a distintos paradigmas de la dignidad humana, nos permite articular los derechos humanos en la historia. ${ }^{22}$

Se puede advertir, dicha afirmación invita a diferenciar en cuál de estos dos paradigmas de dignidad humana se encuentra la persona respecto a su derecho de realizarse en el ámbito sexual de una manera autónoma y libre, pues no se debe perder de vista que aquellas libertades no se logran materializar, debido a una agresión de tal estirpe, y en donde el Estado y sus autoridades, a través de sus normas, no pudieron garantizar ninguno de los paradigmas de esa dignidad humana.

Ahora bien, no se escapa entonces del anterior argumento, el hecho de que resulta obligado tener en cuenta que para lograr tal diferencia debemos comprender claramente el concepto y alcance de la dignidad humana, que en la práctica de la existencia humana tiene varias connotaciones, porque es necesario

...considerar al ser humano como un fin en sí mismo y no como un instrumento o un medio para la realización de la voluntad o intereses ajenos. El principio de dignidad humana protege "i) la autonomía o posibilidad de diseñar un plan vital y de determinarse según sus características (vivir como se quiere), ii) ciertas condiciones materiales de existencia (vivir bien), iii) la intangibilidad de los bienes no patrimoniales, integridad física e integridad moral (vivir sin humillaciones). ${ }^{23}$

\footnotetext{
22 Gaviria Díaz, Carlos, op. cit., p. 10.

23 Corte Constitucional de Colombia, Sentencia T-881 de 2002, M. P.: Eduardo Montealegre Lynett.
}

Esta obra está bajo una Licencia Creative Commons

Atribución-NoComercial-SinDerivar 4.0 Internacional, IIJ-UNAM. 
En ese orden de ideas, teóricamente esos derechos sexuales están y se deben mantener en la gama de los derechos humanos fundamentales; ${ }^{24}$ es decir, al interior del primero de los paradigmas. No obstante lo anterior, también resultaría posible desde una posición filosófica y axiológica, que ninguna categorización resulta plausible en tratándose de este tipo de derechos de tipo sexual.

Este escenario conceptual tiene su fundamento a partir de la fractura de la dignidad humana que surge después de la agresión de un derecho sexual; así: ¿pueden esos derechos sexuales, en consonancia con la dignidad humana, mantenerse como derecho fundamental en ese primer paradigma después de ese episodio? En clave de la no clasificación y categorización de esos derechos humanos, se diría que sí se pueden mantener en ese primer paradigma. Sin embargo, serenamente se puede dejar planteado también que no, pues frente a lo que implica el concepto y precepto de la dignidad humana, ésta no se reivindica fácilmente por el autor del delito, ni siquiera bajo la idea que aquél solamente afectó un poco de ese principio-derechovalor jurídicamente amparado por el Estado, y tampoco la reivindicarán las autoridades públicas. Nótese, ni siquiera con una decisión judicial de condena o responsabilidad penal en ese sentido. ${ }^{25}$

24 "El concepto de derecho fundamental, pese a inspirarse en la realidad y buscar en cierto modo moldearla, es fruto de la consagración o del reconocimiento del derecho positivo, de suerte que se impone encontrarse en un supuesto comprendido dentro de su ámbito material delimitado o supuesto por el Constituyente para poder gozar de él". Corte Constitucional de Colombia, Sentencia T-240 de 1993, M. P.: Eduardo Cifuentes Muñoz.

25 "El derecho a la dignidad humana no es una facultad de la persona para adquirir su dignidad, ni para que el Estado se la otorgue o conceda, porque la dignidad es un atributo esencial de la persona humana; el derecho fundamental es a que se le dé un trato que respete plenamente la dignidad del ser humano. Es un derecho que implica tanto obligaciones de no hacer como obligaciones de hacer por parte del Estado". Corte Constitucional de Colombia, Sentencia T-702 de 2001, M. P.: Marco Gerardo Monroy Cabra. "La dignidad humana como principio fundante del Estado, es el presupuesto esencial de la consagración y efectividad del sistema de derechos y garantías contemplado en la Constitución. Tiene valor absoluto no susceptible de ser limitado bajo ninguna circunstancia, lo que sí ocurre con derechos que necesariamente deben coexistir con otros y admiten variadas restricciones. El respeto a la dignidad humana no sólo es una declaración ética sin una norma jurídica de carácter vinculante para todas las autoridades. Su acato debe inspirar a todas las actuaciones del Estado. Por lo tanto, la dignidad del ser humano constituye razón de ser, principio y fin último de la organización estatal. Bajo este derrotero, la dignidad se erige como un derecho fundamental, de eficacia directa cuyo reconocimiento general compromete el fundamento político del Estado colombiano". Corte Constitucional de Colombia, Sentencia T-792 de 2005, M. P.: Clara Inés Vargas Hernández; véase 
En virtud de lo anterior, vemos cómo esa principal categorización puede quedar reducida a un simple derecho de carácter transitorio; esto es, se tiene incólume el derecho sexual mientras el Estado brinde formal y materialmente las garantías básicas de su protección. Por lo tanto, teniendo en cuenta que una vez que se produce la trasgresión, y al no poderse reparar en el grado sumo para la víctima, se traslada entonces lo anterior a ese segundo paradigma de garantía; lo que refiere solamente a procurar al menos el mantenimiento de las condiciones básicas de todo tipo, sean éstas sicológicas, sociológicas y jurídicas, para que la persona afectada intente nuevamente desarrollarse armónica e integralmente desde su sexualidad, que sin duda nunca será la misma.

Como se ve, no hay cabida entonces para aceptar jurídicamente que existen derechos humanos más importantes que otros, pero sí concepciones filosóficas y axiológicas diferentes respecto de ellos. ${ }^{26}$ Nótese, por ejemplo, que en muchas partes del mundo la característica de la universalidad de los derechos humanos se desintegra, y una muestra de ello son los regímenes punitivos en los que se dispone la pérdida de la vida como pena capital y a la vez como símbolo de una retribución fuerte al victimario. Desde allí, muchas víctimas y sociedad en general lo ven como una clara manifestación de justicia por el daño que se les causa. No obstante, esas muestras quedan reducidas simplemente a la concepción política, cultural y social de esos Estados, en donde la idea sobre los derechos humanos y su universalidad ${ }^{27}$ no lleva implícito ese sello traducido como la única forma de dar lectura al mundo; al menos en tratándose de aquel principio.

también, Sentencia T-395 de 1998, M. P. Alejandro Martínez Caballero; Sentencia T-389 de 2001, MP. Jaime Córdova Triviño; Sentencia T-576 de 2003, M. P. Alfredo Beltrán Sierra; Sentencia T-701 de 2006, MP. Álvaro Tafur Galvis; Sentencia C-397 de 2006, M. P. Jaime Araujo Rentería.

26 "En las discusiones actuales, pasadas y probablemente también en las futuras sobre los derechos humanos, es dable diferenciar — como muy en general en la filosofía política- cuatro posiciones básicas, que pueden denominarse «aristotélica», «hobesiana», «kantiana», y «nietzscheana», refiriéndolas a arquetipos históricos. ... La concepción liberal de los derechos humanos es la idea política central de la Ilustración y de las revoluciones burguesas. Ella constituye hasta hoy el fundamento de todas las Constituciones de tipo occidental. Con esto, es hasta ahora una de las ideas políticas más exitosas". Alexy, Robert, Teoría del discurso y derechos humanos, Bogotá, Universidad Externado de Colombia, 1995, pp. 63 y 66.

27 "Contra la universalidad de los derechos humanos, se arguye que esos derechos serían en verdad solo elementos de una determinada cultura, o sea la de occidente y con 
Se sostiene lo anterior, porque es sabido que en el campo de las concepciones filosóficas y de la misma naturaleza jurídica de los derechos humanos, como también de su práctica y garantía de protección, no existe un solo universo teórico como el anteriormente planteado en esos regímenes para que se pueda dar este castigo, pues éstos responden en gran medida a la obediencia de una autoridad hereditariamente déspota, que infunde temor en la sociedad, y no necesariamente a la lenta y pasiva evolución históricosocial que hoy se piensa, que no se olvide, también es capaz de estructurar un ordenamiento jurídico que refleje en la virtud de las personas la capacidad de conciliar todas las manifestaciones multiculturales, sin entrar a categorizar los derechos humanos, en este caso especial, la vida misma.

Al lado de ello, esto nos conduce a verificar también la característica de la indivisibilidad de los derechos humanos de contenido sexual, en donde a partir de allí no pareciera plausible clasificarlos. No obstante, al existir en el campo normativo aquellas denominaciones tales como los "derechos civiles y políticos", al menos para la mayoría de los países del mundo, se pone entonces de relieve un amplio margen de su fundamentalidad, porque su protección se puede ver expuesta a un argumento de interpretación constitucional. De cualquier modo, la libertad, la integridad y la formación sexual gozan formalmente de protección en ese sentido, pero, se insiste, la constatación de lo anterior y la aceptación de ese statu quo termina por adormecer cualquier intento de protección material que se pretenda solicitar del Estado en cualquier esfera, pues esa aspiración puede verse truncada y a la deriva por la cambiante interpretación constitucional ${ }^{28}$ que requieren los diferentes casos examinados por los tribunales

ello tendrían si acaso una validez relativa o particular. Todo reclamo de validez universal sería imperialismo adornado de humanitarismo. Alexy, Robert, Teoría del discurso y derechos humanos, cit., p. 67.

28 Atienza, Manuel, "Estado de derecho, argumentación e interpretación”, Anuario de Filosofia del Derecho, vol. XIV, 1997, pp. 465-484; Guastini, Riccardo, Estudios sobre la interpretación jurídica, trad. de Mariana Gascón y Miguel Carbonell, México, UNAM, Instituto de Investigaciones Jurídicas, 1999, p. 5; Galán Juárez, Mercedes, “La interpretación de los derechos fundamentales por parte del Tribunal Constitucional, una argumentación en términos de razonabilidad", Isegoría, núm. 35, 2006, pp. 33-55; Fernández Cruz, José Ángel, "La interpretación conforme con la Constitución: una aproximación conceptual”, Ius et Praxis, año 22, núm. 2, 2016, pp. 153-188; Massé Narváez, Carlos E. y Rivera Hernández, Juan, "La hermenéutica en la interpretación conforme de los derechos humanos en el orden jurídico mexicano", Methaodos Revista de Ciencias Sociales, vol. 2, núm. 1, 2014, pp. 36-44; Grández Castro, Pedro P., "Argumentación jurídica y 
de justicia, lo que viene de ser vigilado por parte de la doctrina cuando pretende que cualquier interpretación en clave de los derechos humanos debe ser siempre sistemática, es decir, eligiendo una hermenéutica conforme con la Constitución. ${ }^{29}$ No obstante, todo es susceptible de cambios, por la inescindible conexión con la argumentación iusfundamental, ${ }^{30}$ que en todos los casos termina marcando el horizonte jurisprudencial en aquellos tribunales al momento de la aplicación normativa al caso concreto, bajo la influencia de los derechos fundamentales. ${ }^{31}$

Ahora bien, dentro de este contexto clasificatorio, la inalienabilidad como característica propia de los derechos humanos de estirpe sexual se adhiere al panorama de irrenunciabilidad de los mismos —a excepción del consentimiento - sin coacción o coerción, que por ningún motivo involucra alguna de las dos, puesto que podría ponerse en entredicho que la dignidad es algo a lo cual se puede renunciar. Bajo esta perspectiva, y considerando los derechos sexuales alrededor de una potencial afectación, aquel panorama sólo conduce a reflejar una cruel encrucijada para las víctimas, porque ellas deben ponderar desde todas sus dimensiones humanas entre las dos únicas opciones posibles que son disyuntivas entre sí, y que terminan siendo totalmente en disfavor de aquéella: la renuncia forzada o la alienación de sus derechos sexuales. Téngase en cuenta, lamentablemente en muchos casos, que las víctimas pierden su vida pretendiendo evitar cualquiera de estas dos.

Después de todo, la mayoría de los argumentos resultan ser válidos, y encauzan la idea de que este especial derecho fundamental no tendría por

derecho constitucional", en Landa Arroyo, César (ed.), Derechos fundamentales, Lima, Palestra, 2018, pp. 109-122.

29 Zavala de Alba, Luis Eduardo, "Gobernanza en derechos humanos: hacia una eficacia y eficiencia institucional", Revue québécoise de droit international, Hors-série, mars 2015, pp. 273-288.

30 “...El resultado es que, en virtud de su base, las argumentación iusfundamental está, por cierto, algo más determinada y estructurada racionalmente, pero que la medida y la fuerza de control que con esto se logra son limitadas. Queda todavía una considerable laguna de racionalidad. Esta laguna de racionalidad la llena el procedimiento de la argumentación iusfundamental: del discurso iusfundamental. El discurso iusfundamental es un procedimiento argumentativo en el que lo que se trata es de lograr resultados iusfundamentales correctos sobre la base presentada". Alexy, Robert, Teoría de los derechos fundamentales, Madrid, Centro de Estudios Políticos y Constitucionales, 2002, p. 553.

31 Anzures Gurría, José Juan, "La eficacia horizontal de los derechos fundamentales", Cuestiones Constitucionales, núm. 22, 2010, pp. 3-51. 
qué verse afectado en ninguna de las formas que la irracionalidad humana despliega. Lo anterior, habida cuenta que la situación anómala, acompañada de las dos opciones antes citadas en las que queda la víctima, no son precisamente las que deben orientar el comportamiento de la humanidad. Sobre estos derechos sexuales, afirma Pabón lo siguiente:

Facultad del ser humano de autodeterminar y auto regular su vida sexual; está unida naturalmente a las finalidades específicas de la sexualidad humana y al concepto de dignidad que gravita sobre todo hombre. Así, la libertad sexual no se ha de entender como posibilidad ilimitada de disposición del propio cuerpo, pues este derecho humano presenta determinaciones y límites naturales.

La libertad sexual es facultad y derecho de elegir, aceptar, rechazar y autodeterminar el comportamiento sexual, con necesaria sujeción a los conceptos éticos de la comunidad y al respeto de los derechos ajenos correlativos. $^{32}$

Así las cosas, los derechos sexuales tendrán siempre el carácter de fundamentales, al menos dentro de los contextos sociopolíticos que quieran mantener íntegra la dignidad humana como fundamento y estructura de un Estado, y también como forma de realización del mismo ser; sin embargo, se podrán hallar argumentos filosóficos, religiosos, e incluso políticos, que permitan dar una clasificación diferente a estos derechos, y lo harán en atención a su misma idiosincrasia. A pesar de lo anterior, se espera que siempre sea en clave del respeto por los derechos sexuales ajenos.

Como ya se hizo notar, para nuestro contexto no en vano Colombia decidió hace muchos años apostarle a la práctica uniforme en el tratamiento de los derechos humanos, y por eso internacionalizó ese propósito, en aras de presentar al mundo su intención de ponerse a tono en el marco del respeto por los mismos. Es así como suscribió y ratificó ante la Organización de Estados Americanos (OEA) aquella Convención Americana de Derechos Humanos, la misma que le permitió asumir una serie de obligaciones en aras de garantizar a sus habitantes el máximo goce y ejercicio de los derechos, y, a la vez, le impuso la obligación de adoptar medidas legislativas para la búsqueda de ese fin especial. No obstante, la clasificación que antes era doctrina hoy ya se encuentra incrustada en las prescripciones

32 Pabón Parra, Pedro Alfonso, Delitos sexuales. La sexualidad humana y su protección penal, Bogotá, Doctrina y Ley LTDA, 2005, p. 126.

Esta obra está bajo una Licencia Creative Commons Atribución-NoComercial-SinDerivar 4.0 Internacional, IIJ-UNAM. 
legales, y así lo viene aceptando la sociedad, lo que posibilita la idea de convencernos de que la afectación de los derechos sexuales, independientemente de su grado o nivel, siempre ha de tocar el núcleo esencial de la dignidad humana; pensarlo diferente, sería claramente desnaturalizar los postulados constitucionales sobre la dignidad humana que continuamente precisa la Corte Constitucional en su jurisprudencia.

\section{INSTRUMENTOS JURÍDICOS DE PROTECCIÓN INTERNACIONAL Y NACIONAL DE LOS DERECHOS SEXUALES: UNA MIRADA DESDE LA DOGMÁTICA CONSTITUCIONAL Y PENAL COLOMBIANA}

Una vez las aquellas bases filosóficas de estos derechos, abordemos ahora este sensible tema poniendo en escena las importantes regulaciones normativas desde donde surgen conceptos o definiciones que permiten identificar aquellos marcos de protección de derechos humanos, teniendo en cuenta los órdenes infra y supraconstitucionales, a partir de los cuales se han puesto en marcha otras políticas de atención en Colombia, así como en otros Estados, con el fin de garantizar de manera efectiva el goce de los derechos sexuales.

La definición de la dogmática viene de ser extensiva de lo que se conoce como dogma: "Fundamentos o puntos capitales de todo sistema, ciencia, doctrina o religión". ${ }^{33}$ Desde este escenario conceptual abordaremos las siguientes reflexiones, considerando los dogmas que dichas fuentes jurídicas traen consigo en tratándose de derechos y delitos sexuales, identificando si lo pretendido por el legislador en términos de eficacia mantienen vigente el sustento teórico en la praxis.

\section{Normas internacionales}

Es necesario recordar que aquel objeto que de antaño le han asignado a las normas jurídicas, especialmente las penales, ha sido el de pretender que sea una garantía de regulación de conductas anómalas de los individuos, trayendo consigo prohibiciones; pues esto se valida, incluso serenamente, como quedó expuesto en líneas precedentes, habida cuenta de la irracional y constante manifestación humana. A su turno, las normas de raigambre

\footnotetext{
33 Diccionario de la lengua española.
} 
constitucional, así expuestas de manera general; es decir, las que no traen distinción en su núcleo de protección, no dejan margen de duda, porque con ellas se expresa la garantía en la protección de derechos humanos, sean éstos de mujeres, hombres, niños, niñas y adolescentes de cualquier origen, filiación poblacional, culto, distinción social y política; lo que resulta atinado, por aquello de que la violencia sexual tampoco tiene en cuenta esas diferenciaciones, pues para el agresor en la mayoría de veces esto le resulta insignificante.

No obstante, las prescripciones en las normas internacionales, en la mayoría de las veces las denominan con títulos que, de entrada, tienen un destinatario específico en su protección. Sin embargo, a pesar de que esto puede causar malestar en los otros sectores que consideran sentirse desprotegidos, es necesario reconocer que aquella normativa atiende al clamor de personas y grupos que vienen siendo víctimas de estos flagelos para ese momento histórico en que se expiden las normas. Después de todo, vemos cómo los fenómenos delictuales terminan abarcando al resto de la población antes no tenida en cuenta allí —en ese título-, y, por aquello del principio de igualdad, se terminan extendiendo sus efectos de protección para éstos. Así las cosas, se enunciará la siguiente normativa sin un estricto orden que pretenda reflejar su jerarquización.

Tenemos entonces la existencia de la Convención Interamericana para prevenir, sancionar y erradicar la violencia contra la mujer, más conocida como Convención de Belém do Pará; ${ }^{34}$ la Convención Americana de Derechos Humanos ${ }^{35}$ y su Protocolo adicional en materia de derechos económi-

34 Es el instrumento internacional que brinda protección a las mujeres frente a la violencia. Fue adoptada en Belém do Pará, Brasil, por la Asamblea General de la Organización de Estados Americanos (OEA) el 9 de junio de 1994. A la fecha cuenta con el mayor número de ratificaciones: de los 34 Estados de la OEA, salvo Estados Unidos y Canadá, lo han ratificado los 32 restantes. Colombia se adhirió a esta Convención el 15 de noviembre de 1995, y fue aprobada en la legislación interna mediante la Ley 248, del 29 de diciembre de 1995. Esta convención define la violencia contra la mujer y consagra el derecho de las mujeres a vivir sin violencia. En el artículo 3, la Convención señala que "[t]oda mujer tiene derecho a una vida libre de violencia, tanto en el ámbito público como en el privado", lo cual incluye el derecho a ser libre de discriminación y a ser valorada y educada libre de patrones estereotipados de comportamiento basados en la inferioridad y la subordinación, como se menciona también en el artículo 6, literales a y b.

35 La Convención Americana sobre Derechos Humanos fue aprobada en Colombia mediante la Ley 16 de 1972. Colombia es Estado parte de la Convención desde el 31 de julio de 1973 cuando depositó el instrumento de ratificación ante la Secretaría General 
cos, sociales y culturales, conocido como Protocolo de San Salvador; ${ }^{36}$ la Declaración de los Principios Fundamentales de Justicia para las Víctimas de Delitos y del Abuso del Poder; ${ }^{37}$ los Principios de Bassiouni, acogidos por la Comisión de Derechos Humanos de la ONU mediante la Resolución 2005/35. Asimismo, se cuenta también con un instrumento que protege especialmente a las mujeres frente a la discriminación y la violencia, denominado Convención sobre la Eliminación de todas las Formas de Discriminación contra la Mujer, conocida también con las siglas "CEDAW"; 38 también instrumentos generales como el Pacto Internacional de Derechos

de la OEA. Esta convención genera obligaciones de los Estados partes, de respetar y garantizar el libre y pleno ejercicio de todos los derechos consagrados en esta convención a toda persona, sin ningún tipo de discriminación, entre otros, por motivos de sexo, y de adoptar las medidas legislativas o de otro carácter que sean necesarias para garantizar la efectividad de los derechos protegidos por la Convención.

36 El Protocolo de San Salvador fue adoptado por la Asamblea General de la OEA el 17 de noviembre de 1988, en la ciudad de San Salvador, El Salvador. El Protocolo fue aprobado en Colombia mediante la Ley 319 de 1996.

37 Adoptada por la Resolución 40/34 de la Asamblea General, del 29 de noviembre de 1985. El principio 6 de la Declaración sobre los Principios Fundamentales de Justicia para las Víctimas de Delitos y del Abuso de Poder establece: "Se facilitará la adecuación de los procedimientos judiciales y administrativos a las necesidades de las víctimas: (a) Informando a las víctimas de su papel y del alcance, el desarrollo cronológico y la marcha de las actuaciones, así como de la decisión de sus causas, especialmente cuando se trate de delitos graves y cuando hayan solicitado esa información".

Véase también el principio 18 de los Principios y directrices básicos sobre el derecho de las víctimas de violaciones manifiestas de las normas internacionales de derechos humanos y de violaciones graves del derecho internacional humanitario a interponer recursos y obtener reparaciones: "Conforme al derecho interno y al derecho internacional, y teniendo en cuenta las circunstancias de cada caso, se debería dar a las víctimas de violaciones manifiestas de las normas internacionales de derechos humanos y de violaciones graves del derecho internacional humanitario, de forma apropiada y proporcional a la gravedad de la violación y a las circunstancias de cada caso, una reparación plena y efectiva, según se indica en los principios 19 a 23, en las formas siguientes: restitución, indemnización, rehabilitación, satisfacción y garantías de no repetición”.

38 La CEDAW fue adoptada por la Asamblea General de la ONU el 18 de diciembre de 1979 y entró en vigor el 3 de septiembre de 1981. En Colombia fue aprobada mediante la Ley 51, del 2 de junio de 1981. La CEDAW, en su artículo 1, define a la discriminación contra la mujer como toda distinción, exclusión o restricción basada en el sexo que tenga por objeto o por resultado menoscabar o anular el reconocimiento, goce o ejercicio por la mujer, independientemente de su estado civil, sobre la base de la igualdad del hombre y la mujer, de los derechos humanos y las libertades fundamentales en las esferas política, económica, social, cultural y civil o en cualquier otra esfera. 
Civiles y Políticos; ${ }^{39}$ y el Pacto Internacional de Derechos Económicos, Sociales y Culturales. ${ }^{40}$ En igual sentido, están la Declaración de Viena sobre la Eliminación de la Violencia contra la Mujer; ${ }^{41}$ las resoluciones del Consejo de Seguridad de Naciones Unidas sobre la protección de las mujeres frente a la violencia y la discriminación en los conflictos armados ${ }^{42}$ y el Estatuto de Roma de la Corte Penal Internacional. ${ }^{43}$

Todo lo anterior, al ser visto desde una perspectiva positiva, nos puede reflejar que existe una enorme garantía formal para todas las personas habitantes en aquellos Estados que se hicieron parte y acogieron para sí estos instrumentos jurídicos, como el caso colombiano.

Después de todo, a la luz de esta normativa tampoco surgen dudas del compromiso internacional de proteger los derechos de la mujer, de manera especial los sexuales. No obstante, no debe olvidarse que de estas normas supraconstitucionales no surge el resultado inmediato al que están convocadas a producir, pues ese intento de protección se presenta inicialmente como un ideal común de los Estados partes en ese campo iusfundamental de las personas, y son éstos los que han de adecuar sus órdenes jurídicos internos para lograr los efectos que se esperan, lo que implica el conocimiento claro de la sociedad que se tiene. Al menos, se cree que lo anterior parece responder a esa estructura tridimensional sobre la cual puede verse el derecho (sociológica, axiológica y jurídica), o, lo que es lo mismo, he-

39 El Pacto Internacional de Derechos Civiles y Políticos fue aprobado por la Asamblea General de la ONU el 16 de diciembre de 1966, y entró en vigor el 23 de marzo de 1976. Fue aprobado en Colombia mediante la Ley 74 de 1968.

40 El Pacto Internacional de Derechos Económicos, Sociales y Culturales fue aprobado por la Asamblea General de la ONU el 16 de diciembre de 1966 y entró en vigor el 23 de marzo de 1976. Fue aprobado en Colombia mediante la Ley 74 de 1968.

41 Adoptada mediante Resolución de la Asamblea General, número 48/104, del 20 de diciembre de 1993. La Declaración reconoce la urgente necesidad de la aplicación universal a la mujer de los principios y derechos a la igualdad, seguridad, libertad, integridad y dignidad.

42 La violencia contra las mujeres en aspectos de género, como también en el marco de los conflictos armados ha sido abordada por instrumentos internacionales, como las resoluciones 1325 de 2000, 1612 de 2005, 1820 de 2008, 1888 de 2009, 1889 de 2009, 1960 de 2010 adoptadas por el Consejo de Seguridad de Naciones Unidas y vigentes para Colombia.

43 Fue adoptado en Roma el 17 de julio de 1998 durante la Conferencia diplomática de plenipotenciarios de las Naciones Unidas sobre el establecimiento de una Corte Penal Internacional. El Estatuto entró en vigor el 1 de julio de 2002. Colombia lo aprobó mediante la Ley 742 de 2002 y depositó el instrumento de ratificación el 5 de agosto de 2002. 
cho, valor y norma, ${ }^{44}$ que pretende atender la visión de un mundo pensado desde todas las dimensiones humanas.

\section{Normas nacionales}

En el orden nacional colombiano fue sólo hasta la Convención de Belém do Pará cuando se dieron signos de regulación normativa con fines de protección de los derechos a "la integridad y el pudor sexual", especialmente de las mujeres, y como ejemplo de ello están los códigos penales de 1837, 1863, 1890, 1936, proyectos de 1974, 1978 y revisión del proyecto de 1979 hasta el Código Penal de 1980. Sin embargo, este último presentaba su regulación un poco arcaica, porque su modo de prohibición obedecía a aspectos morales y religiosos; tanto así, que si cualquiera de los autores o partícipes de una agresión sexual contraía posteriormente un matrimonio válido con el sujeto pasivo — víctima—, procedía jurídicamente la extinción de la acción penal; es decir, aun para esta época dicha posibilidad todavía parecía atender referentes religiosos.

Avanzando en el tiempo, se expidió una nueva Constitución política en 1991, que trajo consigo un marco de tratamiento igualitario y la prohibición de discriminación en su artículo 13, al igual que la protección a la familia en todo su núcleo en el artículo 42. En virtud de esa constitucionalización de derechos, surgió la reforma del código de 1980 bajo la Ley 360 de 1997, en donde cambió de nombre a los bienes jurídicamente protegidos y también aumentó las penas en esos delitos sexuales. Asimismo, tratando de armonizar las obligaciones internacionales adquiridas en materia de derechos humanos, reguló aspectos relativos al tratamiento dentro de las investigaciones penales que se adelantaran, y de manera especial relacionó acertadamente la protección y prevención de enfermedades de transmisión sexual que pudieran ser producto del injusto.

Posteriormente, la Ley 599 de 2000, actual Código Penal de Colombia, redefinió nuevamente el concepto de estos delitos y los denominó "contra la integridad, libertad y formación sexuales", pero rebajando las penas a imponer. Al lado de ellos, con la expedición de la Ley 1236 de 2008 se aumentaron las penas de prisión así: para acceso carnal violento, que estaba de ocho a quince años, fue fijada entre doce y veinte años, el acto sexual

\footnotetext{
44 Reale, Miguel, Teoría tridimensional do direito, São Paolo, Saraiva, 1968, pp. 119-121.
} 
violento, que estaba de tres a seis años, la aumentó dejándola entre ocho y dieciséis años; el acceso carnal o acto sexual violento en persona puesta en incapacidad de resistir, que estaba entre ocho y quince, la aumentó para dejarla entre doce y veinte años; el acceso carnal abusivo con menor de catorce años, que estaba de cuatro a ocho, quedó entre doce y veinte años; los actos sexuales con menor de catorce años, que se castigaba con tres y cinco años, la fijó entre nueve y trece años; el acceso carnal o acto sexual abusivos con incapaz de resistir, era de cuatro a ocho años, y quedó entre doce y veinte años.

Con sano criterio frente a estos delitos, el legislador prescribió que la pena se puede aumentar si el delito produce embarazo o contaminación de enfermedad de transmisión sexual, o si se realizare sobre el cónyuge o sobre la persona con quien se cohabite o se haya cohabitado, o con la persona con quien se haya procreado un hijo. A este propósito se le sumó la expedición de la Ley 1257 de 2008, que quiso garantizar a todas las mujeres una vida libre de violencia en todos los ámbitos, y a su vez se amplió el espectro de interpretación de este delito constituyéndolo también como violencia de género. Del mismo modo, el legislador quiso proteger muchos de esos derechos sexuales que venían siendo atentados bajo el modelo de la trata de personas, y por eso creó la Ley 985 de 2005, introduciendo un nuevo artículo a la legislación penal vigente que contemplara tal fenómeno delictual, y así entonces quedó penalizada con pena de trece a veintitres años de prisión y multa de ochocientos a mil quinientos salarios mínimos legales mensuales vigentes.

A su turno, conviene decir que la Ley 599 de 2000 quiso ponerse a tono en materia de derecho internacional humanitario por aquello de los delitos que se venían cometiendo en el marco del conflicto armado colombiano, y fue por eso que pretendió armonizar su regulación, tocando temas en su título I, denominado "Delitos contra la vida y la integridad personal", y surgió el agravante respecto del embarazo forzado. De la misma manera, plasma en el titulo II, los "Delitos contra personas y bienes protegidos por el derecho internacional humanitario", entre éstos: los delitos de homicidio, lesiones personales, tortura, acceso carnal violento y acto sexual violento en persona protegida, como también los delitos de prostitución forzada y de esclavitud sexual.

Podemos ver también, por ejemplo, los cambios suscitados en la Constitución Política mediante el Acto Legislativo 3 de 2002, que modifica el numeral 6 del artículo 250 constitucional, que diera paso a la vigente Ley 
906/04, actual Código de Procedimiento Penal. Todo esto con el fin de proteger, asistir, reparar y restablecer los derechos de las víctimas en todo el proceso penal, así como lo pudo establecer el legislador en los artículos 11 y 14, y el capítulo IV del título IV de la referida Ley.

Coetáneamente se mantiene vigente la Ley 600 de 2000, también del procedimiento penal, teniendo en cuenta que en ambos procedimientos se resalta la forma de investigar y juzgar esta clase de delitos de manera diferente en cada momento histórico de su vigencia, pero hay que resaltar que el marco sustancial o núcleo de protección es uno solo: la libertad, la integridad y la formación sexuales, los cuales se busca garantizar.

De este modo, se presenta entonces la existencia de una evolución normativa formalmente válida para nuestra sociedad, con miras a lograr los objetivos de protección que constantemente se propone el Estado colombiano; pero si bien todo este esfuerzo legislativo es importante y debe aplaudirse, no podemos alejar de este análisis, que no basta con estos grandes y extensos referentes legislativos que pretenden blindar los derechos sexuales de las personas al interior de un grupo de aquellas que se muestra irracional frente a esta tutela jurídica internacional y nacional, pues la atención que hoy exige nuestra sociedad desde el punto de vista de la protección y la conjuración del fenómeno, es que dichos dogmas de protección no deben llegar a confundirse con la eficacia material que debe ser siempre el efecto útil de las normas jurídicas, a pesar de que se presenten relaciones necesarias sobre este propósito desde su validez formal. ${ }^{45}$

Nótese que todos estos presupuestos jurídicos gravitan alrededor de la dignidad humana, teniendo en cuenta que este es el principio consagrado por nuestra Constitución Política desde su primer artículo, a partir del cual se estructura políticamente a Colombia con una mirada ontológica bajo el modelo de Estado social y democrático de derecho. ${ }^{46}$

Debe quedar claro que el constituyente primario desde su expresión soberana, y el Congreso de la República, como secundario en esa tarea de protección, vienen de ser muy acertados en materia de dignidad humana, y ahora en esa misma clave lo hace y ratifica constantemente la Corte Constitucional, al interpretar que ese principio, derecho o valor que se conoce como dignidad humana se hace notar como un concepto amplio,

\footnotetext{
45 Kelsen, Hans, Validez y eficacia del derecho, Buenos Aires, Astrea, 2005, pp. 49-60.

46 Corte Constitucional de Colombia, Sentencia T-585 de 2008, M. P.: Humberto Sierra Porto.
} 
que de paso le otorga nuevamente vida a la afirmación de Gustavo Zagrebelsky cuando considera que "lo que es verdaderamente importante por el mero hecho de serlo, nunca puede ser puesto, sino que debe ser siempre presupuesto". ${ }^{47}$

Retomando el panorama constitucional interno, vemos otras formas de protección en los artículos 12 y 17, que tratan sobre la prohibición de tratos crueles, inhumanos o degradantes, como la servidumbre, la esclavitud y el tráfico de personas. De igual manera, se protege especialmente a los niños, las niñas y los adolescentes sobre toda forma de abandono, explotación sexual, venta, secuestro, violencia física o moral, explotación laboral y turismo sexual; armonizando lo anterior dentro del marco legal de la Ley 1098 de 2006, que es el vigente Código de la Infancia y la Adolescencia, que en sus artículos 2, 192, 193, 194, 195, 196, 197 y 198 establece procedimientos especiales cuando los menores y adolescentes sean víctimas de delitos.

En ese sentido, Colombia tampoco aplazó su compromiso internacional que permitía armonizar tales intentos de protección expuestos en la parte dogmática de su Constitución Política, y fue por eso que suscribió el Protocolo Adicional de los Convenios de Ginebra de 1949 (Protocolo I), que fue ratificado por el Estado colombiano, y que trata sobre los conflictos armados internacionales. Tal contenido normativo obliga y ordena a los Estados a respetar a las personas, y esto se presenta desde su mejor ámbito de protección cuando prohíbe todo acto contra la dignidad humana, como aquellos basados en los tratos crueles y humillantes, la prostitución forzada y cualquier otro atentado contra el pudor sexual.

\section{La Corte Constitucional: una jurisprudencia del clamor social}

Dentro de este contexto, resulta oportuno referirnos nuevamente a la intervención de la Corte Constitucional en su intento de protección, claro está, ya por la vía judicial. Para lo anterior, nos debemos ubicar en 2008, cuando esa Corte emitió el auto 092, en el cual abordó temas como el desplazamiento forzado y el fenómeno de la violencia sexual ocurrida en el marco del conflicto armado ${ }^{48}$ y a partir de allí ordenó una clase de

47 Zagrebelsky, Gustavo, El derecho dúctil. El derecho por principios, Madrid, Trotta, 2008, p. 9.

48 Corte Constitucional de Colombia, Auto 092 de 2008, M. P.: Manuel José Cepeda Espinosa. En aquel pronunciamiento se pidió al Estado que creara trece programas para 
medidas referentes a la investigación en muchos de los casos presentados, con el fin de evitar la impunidad; además, la intervención judicial también buscó que realmente se pudiera hallar esa atención integral que deben tener aquellas víctimas en caso de no lograr esa protección que se propone el Estado. De la anterior tesis constitucional por vía judicial, se puede extraer nuevamente el mensaje del fracaso en que ha caído el derecho positivo y la institucionalidad para proteger los derechos sexuales de los colombianos.

Lo anterior, implicó necesariamente para el Legislativo, replantear los puntos de partida en busca de ese propósito de protección; por eso, vemos entonces cómo el artículo 5o. del Decreto 4796 de 2011 dispuso que en nuestro país se adoptara un protocolo específico en esa materia, y su justificación se radicó especialmente por tener ya una connotación de problema de salud pública; esto condujo a que desde el Ministerio de Salud y Protección Social se expidiera el Protocolo de Atención Integral en Salud para Víctimas de Violencia Sexual, pretendiendo que las entidades prestadoras de esos servicios tuvieran claro el modelo de atención, el mismo que como un referente ya se encontraba al interior del Convenio 620 de 2010, celebrado entre ese Ministerio y el Fondo de Población de las Naciones Unidas.

De acuerdo con lo anterior, el producto normativo que antecede a la adopción de este protocolo ha involucrado de manera efectiva gran parte de las instituciones del Estado, con miras a lograr el objetivo trazado; así como se puede verificar a través de la Ley 1146 de 2007, que se expide con fines de prevención "de la violencia sexual y atención integral de los niños, niñas y adolescentes abusados sexualmente"; y también la Ley 1257 de 2008, ya referida anteriormente, que prevé normas "de sensibilización, prevención y sanción de formas de violencia y discriminación contra las mujeres", y presenta, a su vez, un catálogo de derechos que le asisten a las víctimas de violencia, y poder así permitirles el acceso a la atención integral por vía de una cobertura médica accesible, suficiente y con calidad.

prevenir la violencia sexual y proteger a las víctimas, y pidió a la Fiscalía General de la Nación que avanzara en la investigación de 183 casos de violencia sexual. Véase también, Mesa de seguimiento al Auto 092 de la Corte Constitucional, Acceso a la justicia para mujeres víctimas de violencia sexual, Cuarto Informe de Seguimiento al Auto 092 de 2008, Bogotá, Antropos, mayo 2011. 
De igual modo, se suma a ese propósito la expedición del Decreto 2734 de 2012, que tiene por objeto "establecer los criterios, condiciones y procedimiento para el otorgamiento de las medidas de atención definidas en el artículo 19 de la Ley 1257 de 2008", y define los lineamientos de los diferentes actores del Sistema General de Seguridad Social en Salud - SGSSS - y las autoridades competentes, para ordenarlas en el marco de las responsabilidades que les fueron asignadas mediante dicha Ley y sus decretos reglamentarios 4796 y 4799 de 2011.

Asimismo, se establecieron en los artículos 19, 21 y 54 de la Ley 1438 de 2011, algunas reformas en el Sistema General de Seguridad Social en Salud, en los que su nuevo diseño estableció derechos y obligaciones respecto de los niños, niñas, adolescentes y mujeres víctimas de la violencia en sus diferentes manifestaciones. Igualmente, la Ley 1448 de 2011, que se conoce como "Ley de víctimas y restitución de tierras", trajo consigo nuevos enfoques diferenciales.

$\mathrm{Y}$ es que en tratándose de medidas eficaces para contrarrestar los delitos sexuales, resulta pertinente relacionar también lo dicho anteriormente por la jurisprudencia constitucional mediante la sentencia C-292/97, en la cual, al hacer un examen de constitucionalidad de algunas normas contenidas en la Ley 360/97, se refirió a la obligación que tienen las autoridades a partir del artículo segundo de nuestra Constitución Política, de no desconocer el clamor de la sociedad cuando la proliferación de los delitos sexuales se hace evidente. Se suma a lo anterior, el llamado para que el legislador, dentro del marco de su discrecionalidad, no sea indiferente para crear y modificar las normas que estima convenientes, y más cuando se trata de menores de edad; teniendo en cuenta que aquellas personas no solamente son víctimas del terrorismo y del desplazamiento forzado, sino también del delito sexual que se presenta de manera constante en esos territorios, y donde los victimarios son los integrantes de los grupos al margen de la ley como también de los agentes del Estado.99

Así, pues, en ese escenario del poder público también se pudo crear la Ley de la República, 1719, de junio 18 de 2014, que reformó algunos artículos de la Ley 599/00 y de la Ley 906/04, que tiene por objeto "la adopción de medidas para garantizar el derecho de acceso a la justicia de las víctimas de violencia sexual, en especial de la violencia sexual

49 Corte Constitucional de Colombia, Sentencia C-292 de 1997, M. P.: José Gregorio Hernández. 
asociada al conflicto armado interno. Estas medidas buscan atender de manera prioritaria las necesidades de las mujeres, niñas, niños y adolescentes víctimas".

Al llegar a este punto, se debe destacar que si bien es cierto que se establecen allí ciertas garantías en materia de investigación y juzgamiento, y un ejemplo de ello lo presenta el contenido de los artículos 13 y 14 de la citada Ley, no es menos cierto que en lo referente para que ese delito cometido al interior del conflicto armado pueda ser o no catalogado como de lesa humanidad, el legislador supeditó dicha posibilidad en el artículo 15 , bajo el contexto en el cual se entenderían como "crimen de lesa humanidad" los actos de violencia sexual cuando se cometan como parte de un ataque generalizado o sistemático contra la población civil y con conocimiento de dicho ataque. Lo anterior, de conformidad con las definiciones del artículo $\underline{7}$ o del Estatuto de Roma y los elementos que esos crímenes así como han quedado desarrollados dentro de ese Estatuto. Por lo tanto, en este contexto resultará de especial atención examinar sociojurídicamente los alcances y riesgos de la investigación criminal y del conocimiento para condenar, por cuanto allí se puede poner en evidencia un problema mayúsculo respecto de los elementos que pueden o no estructurar ese delito para poder catalogarlo como de lesa humanidad, y, de paso, porque los análisis obligarán al estudio de las problemáticas que también surgirán en materia de reparación económica o simbólica, en consonancia con lo que el legislador también ha permitido en su momento mediante leyes transicionales para lograr la paz estable y duradera en nuestro país, especialmente la surgida últimamente con los acuerdos de paz en La Habana, Cuba, con las FARC, en donde no existe una clara separación de estos delitos sexuales; es decir, este delito en tales circunstancias puede verse dentro de la gama de aquellos que son conexos con el conflicto armado, al menos es lo que parece reflejar el acuerdo con este grupo y la ley estatutaria que los materializa, lo que implicaría en tiempo no lejano un antecedente nefasto frente a la sociedad, como también frente a futuros acuerdos con otros grupos al margen de la ley, en donde las víctimas de este delito en aquellos contextos del conflicto armado habrán preferido no nacer, como tampoco lo pudieron hacer sus hijos, algunos producto de relaciones consentidas, pero otros como consecuencia de esos sometimientos y violaciones.

Como antítesis de lo anterior, y considerando nuevamente el contexto de conflicto armado colombiano, el clamor social exige que este aspecto 
no se torne ambiguo, al menos desde la connotación que tienen esos delitos sexuales en aquel posible catálogo normativo dentro de ese escenario, dado que la menor exigencia es que aun si fueron cometidos dentro del conflicto armado no puedan tener la posibilidad de tener beneficios en su juzgamiento alrededor de una justicia especial, pues es apenas justo que así sea, por cuanto aquel fenómeno específico del conflicto ya bastante lo ha soportado gran parte de la población, y ahora se le quieran sumar aquellos atentados contra la libertad sexual que también sufrieron muchas personas en esos contextos armados, y terminen blindándose bajo este panorama legal y judicial aquellos victimarios que creyeron que los derechos sexuales también podían ser trasgredidos, bajo la idea, incluso desdibujada, de que estos delitos hacían parte y son conexos al conflicto armado. No obstante, las evidencias empíricas nos permiten sostener que esto no solamente cabe en la mente de los victimarios, sino que termina siendo otra concesión que conscientemente el gobierno y los legisladores comprometen frente al presunto logro de la paz.

Sin embargo, se puede sostener que frente al derecho insoslayable de la dignidad y la igualdad constitucional que se irradia en un mismo núcleo fundamental de protección, no resulta prudente diferenciarla frente al ser humano y bajo ninguna circunstancia; es decir, no deben ser menos exigentes la investigación y el juzgamiento de ese delito sexual en las condiciones normales que también otras personas lo sufren, valga precisarlo, de aquellas víctimas que sin estar en territorios donde no se verifica de lleno el conflicto armado, también terminan soportando ese flagelo; por ejemplo, los acontecidos en zonas urbanas y semirrurales, incluso, de manera más generalizada. De mantenerse esta diferenciación dentro del ordenamiento jurídico, siempre será probable que se sigan manifestando las tensiones dialécticas, y más si lo que se pretende es darle validez a una dogmática constitucional que categoriza al individuo, como si sólo se tratara de la división coherente de incisos o parágrafos de un artículo, pues esa reflexión sociojurídica, en un tiempo no lejano reclamara con más vehemencia el disfrute de la libertad y la integridad sexual, sin que merezcan tal distinción y tratamiento por parte del mismo legislador. No se olvide, que el victimario parece comprender desde su misma irracionalidad, que se enfrenta a una constante fractura del dogma jurídico de protección de los derechos sexuales del otro. 


\section{UNA REVISIÓN AL DOGMA DE LA GARANTÍA DE LOS DERECHOS SEXUALES}

Debemos por último plasmar algunas ideas que serenamente pretenden dar una mirada diferente al paradigma que sigue sosteniendo que la eficacia en la protección de los derechos sexuales debe ser exigida de un sistema jurídico meramente positivo, cuando las evidencias demuestran sin vacilación que esa garantía de protección también depende de la superación de otros factores reales en la sociedad, y que en los contenidos normativos lentamente se viene reflejando.

Bajo esta línea de argumentación nos podemos referir, claro está, de una manera diferenciada, teniendo en cuenta a la sociedad cuando ha expresado su clamor y ha puesto al legislador en una encrucijada en materia de política criminal con miras a las sanciones penales que requieren este tipo de delitos sexuales; por ejemplo, la exigencia de penas perpetuas, y entre líneas, enervadamente reclaman la pena capital, y lo hacen ante situaciones o casos específicos en los cuales el agresor ha desbordado la irracionalidad, la infamia y la indolencia con sus actos.

Dichas manifestaciones alrededor del anterior panorama punitivo y su conveniencia no se escapan del ejercicio racional en el escenario legislativo y se acompañan de manera regular de los argumentos del ilustre maestro Beccaria, cuando sobre este tipo de sanciones, y a partir de sus axiomas psicológicos, expresó lo siguiente:

No es la intensidad de la pena lo que hace mayor efecto sobre el ánimo humano, sino su duración; porque nuestra sensibilidad es más fácil y establemente movida por mínimas pero repetidas impresiones, que por un fuerte pero pasajero impulso... No es el terrible pero pasajero espectáculo de la muerte de un criminal, sino el largo y penoso ejemplo de un hombre privado de libertad, que convertido en bestia de servicio recompensa con sus fatigas a la sociedad que ha ofendido, lo que constituye el freno más fuerte contra los delitos... ${ }^{50}$

Por lo tanto, considerando cualquiera de los contextos, y si pensamos que las anteriores enunciaciones jurídicas pueden llegar a prescribirse nuevamente en nuestra sociedad, entendida ésta como aquella posibilidad

50 Beccaria, Cesare, De los delitos y las penas, trad. de Francisco Tomás y Valiente, Madrid, Aguilar, 1982, pp. 116 y 117. 
para que el orden constitucional y penal sea realmente eficaz frente a la protección de los derechos sexuales, $\mathrm{y}$, en consecuencia, se logre disuadir al individuo para que comprenda que el respeto en la sexualidad del otro es el comportamiento esperado en sociedad; todo lo anterior tendrá que traer consigo la superación, entre otros aspectos, de los dogmas de la filosofía moral y humanista que irradia ese marco de protección a la libertad y a la vida misma. En otras palabras, deberá verificarse que los presupuestos morales, religiosos, sociales, institucionales y otros más, ${ }^{51}$ se puedan encauzar en el conglomerado creyendo que aquel desarrollo legal propuesto en esos términos puede ser eficaz frente a ese fin que se persigue, es decir, la erradicación definitiva de los delitos sexuales.

A diferencia de lo anterior, resulta evidente desde la misma praxis, que ninguna política criminal en el mundo acompañada incluso de sus divinas y virtuosas leyes, sin olvidar que históricamente han sido drásticas en algunas latitudes,${ }^{52} \mathrm{y}$ en donde el caso de nuestro Estado colombiano no ha sido la excepción, ha podido lograr la erradicación, y tampoco minimizado el flagelo del delito sexual; de hecho, las normas penales, cuando se erigen con su objeto y finalidad sancionatoria frente al delito sexual, se hacen notables también, porque paralelamente vienen acompañadas de aspectos preventivos y de atención integral a las víctimas del mismo, lo cual, desde la dialéctica planteada en su texto, puede tener sentido, pero desde la lógica jurídica presuponen textualmente su ineficacia a partir de su mismo acto creación; es decir, no se corresponde con el dogma de eficacia pretendido, al punto que se puede serenamente afirmar, que ese defecto se predica des-

51 "El deber del magistrado civil consiste en preservar y asegurar a la generalidad del pueblo y a todos y cada uno de sus súbditos en particular, mediante la aplicación imparcial de leyes justas, la justa posesión de aquellas cosas que pertenecen a su vida. Si alguno pretende violar esas leyes y oponerse a la justicia y al derecho, su pretensión se verá restringida por el miedo al castigo, el cual consiste en la privación disminución de esos bienes civiles que normalmente tendría la posibilidad y el derecho de disfrutar. Pero en vista de que ningún hombre soporta voluntariamente ser castigado con la privación de alguna parte de sus bienes y, mucho menos, de su libertad o de su vida, el magistrado se encuentra, por lo tanto, armado con esta fuerza: el apoyo de todos sus súbditos, a fin de castigar a aquellos que violan los derechos de los demás”. Locke, John, Ensayo y carta sobre la tolerancia, trad. española de Carlos Mellizo, Madrid, Alianza Editorial, 1999, p. 56.

52 La ley del Talión. Talión significa tal pena cual delito, y en tal sentido material se aplicó inicialmente. Se enunciaba diciendo "ojo por ojo, diente por diente, miembro por miembro", etcétera. Se le encuentra en la Biblia, en Éxodo, y en el Código de Hammurabi, promulgado por Hammurabi, rey de Babilonia, que reinó de 1955 a 1912 a. C. 
de que el prospecto de norma viene inquietando la mente del legislador, y ésa puede ser una de las razones por las cuales no se aventura a predicar resultados imposibles de logar; sin embargo, no se olvide que desde el populismo político y punitivo muchos legisladores aprovechan las coyunturas del fenómeno delictual para así proponer su creación jurídica.

Se infiere de lo anterior, que en un sistema jurídico como el nuestro esto parece ser lógicamente pensado para diferenciar la validez de la eficacia, pues si bien es cierto que por la observancia de sus procedimientos formales en la creación, como también por la armonía que guarda a través de su sistemática aplicación por parte de los tribunales, no se pone en duda su validez, porque además, ésta ha sido identificada claramente como derecho en esos escenarios judiciales, y no ha sido cuestionada en ese sentido. No obstante, no se debe perder de vista que dichas reglas en muchas ocasiones presentan paralelamente criterios de eficacia, y éstos sí ponen en duda los efectos, no precisamente porque la regla prescriba en sí misma su ineficacia por el desuso, ${ }^{53}$ sino mejor, porque al menos en nuestro contexto, al usarlas, no generan el resultado vinculado en su mismo contenido, que viene de ser indiscutiblemente válido. Asimismo, se puede asociar este aspecto a la posibilidad que existe en el grupo social de ser un mero observador de las normas, sin que ello implique su aceptación, o aceptarlas y tenerlas como guía de acción de su conducta, ${ }^{54} \mathrm{o}$, desde otro ángulo filosófico, este fenómeno puede presentarse porque desde un criterio valorativo no resulta ser moralmente obligatoria la norma por el mero hecho de serlo, así como lo pueden considerar las ideologías seudopositivistas. ${ }^{55}$

Visto lo anterior, la eficacia que contienen las normas jurídicas en materia de protección de los derechos sexuales en Colombia, falaz por antonomasia, viene aparejada también de la desconfianza e inseguridad de que el respeto por los derechos sexuales del otro aún no ha alcanzado el grado de madurez y de razonamiento social suficiente, escenario en el cual nos permite pensar, que más allá de la desbordante creación de las normas jurídicas, lo realmente necesario es la exigente enseñanza y asimilación de

\footnotetext{
53 Hart, H. L. A., El concepto de derecho, Buenos Aires, Abeledo-Perrot, 2007, pp. $125-137$.

54 Ibidem, pp. 110 y 111.

55 Roos, Alf, El concepto de validez y otros ensayos, Buenos Aires, Centro Editor de América Latina, 1968, pp. 21-55; Bobbio, Norberto, El problema del positivismo jurídico, Buenos Aires, Eudeba, 1965, pp. 37-64.
} 
una escala axiológica debidamente empoderada en la sociedad, en donde sea el respeto por los derechos sexuales del otro el que se presente como el principal valor y pueda convertirse en una constante fórmula de protección y barrera frente a la trasgresión.

Como vimos en líneas precedentes, resulta ser amplia la producción normativa internacional y nacional que nuestro Estado colombiano viene adoptando encaminado a proteger los derechos sexuales, evidenciando que aquellas prescripciones pretenden garantizarlos en toda su dimensión a partir de una adecuada sistemática jurídica. Sin embargo, conviene distinguir que el panorama que hasta ahora se nos presenta en sociedad nos desprende la idea de que su eficacia, en clave de protección y disuasión para la no agresión sexual, quedó suspendida en un trayecto de doble vía, valga decirlo, aplazada y desplazada.

Hablamos de aplazada, por cuanto se sigue evidenciando la continuidad del flagelo, y al menos no será esta generación y probablemente muchas más, las que puedan ver cumplidos los fines que se propuso nuestra Constitución y sus leyes; y desplazada, por cuanto al seguirse presentando tal fenómeno, y al haber puesto en cuestión la eficacia de las normas sustantivas, se tendrá que seguir acudiendo a las normas adjetivas de tipo penal que tratan la investigación y el juzgamiento de esos delitos sexuales. Lo anterior, con la esperanza de que aquellos delitos no queden reducidos a la impunidad. No obstante, dicha suspensión en doble vía en los términos descritos parece ser una característica surgida desde los mismos albores de la humanidad, donde coexistieron leyes divinas y humanas, pues, se reitera, los delitos sexuales se constatan de muy vieja data.

Con sano criterio, se puede sostener que una elaboración normativa en la actualidad, que no cumpla con esos presupuestos de eficacia, puede seguir corriendo el riesgo de quedarse simplemente en una mera enunciación jurídica, en donde el único efecto que podrá lograr será el de la eficacia simbólica, que tiene su fundamento a partir del análisis que de la conducta social se hace, con la conducta motivada en la norma, sobre la cual se afirma, aquella con el paso del tiempo pierde su eficacia, e incluso su validez..$^{56}$

56 Botero Bernal, Andrés, Diagnóstico de la eficacia del derecho en Colombia y otros ensayos, Medellín, Biogénesis, 2003, p. 35; véase también Kelsen, Hans, Validez y eficacia del derecho, cit., p. 71; Walter, Robert, Validez y eficacia del derecho, Buenos Aires, Astrea, 2005, p. 10; Bulygin, Eugenio, Validez y eficacia del derecho, Buenos Aires, Astrea, 2005, pp. 106-108; Bulygin, Eugenio y Mendonca, Daniel, Normas y sistemas 
En última instancia, verificada la pérdida de eficacia y validez de la norma jurídica al no lograr materializar su finalidad, ${ }^{57}$ conduce necesariamente a pensar que se verán irrumpidos constantemente aquellos derechos sexuales y, de paso, en la imposibilidad de ver cumplidos los postulados jurisprudenciales en clave iusfundamental, al no poder conocer la verdad real de los hechos victimizantes, así como bien lo ha podido interpretar la Corte Constitucional en la sentencia C-454/06, ${ }^{58}$ y que fuera reforzada posteriormente con la sentencia C-209 de 2007, ${ }^{59}$ que quieren mantener vigente el contenido filosófico y axiológico de la ley, aunque su estructura jurídica varíe con el tiempo.

Para finalizar, una buena clave para asimilar aquella paradoja del derecho, es que puede resultar necesario que aceptemos de una vez por todas, que si bien es cierto su función también es servir de límite al poder, que a veces se expresa mediante la fuerza del Estado, estos dos elementos - poder y fuerza- deben estar siempre unidos y al servicio de la sociedad. Lo anterior, porque la función dual que surge de esta sinergia es precisamente distanciar con todo su rigor a quien irrespeta los derechos sexuales del otro, porque de lo contrario, al imponerse aquél por la falta de cohesión o relación disfuncional entre estos dos, suele ser fatal para un Estado de derecho en el cual sus normas jurídicas siempre gozarán de una presunción de validez, pero sin olvidar que bajo estos contextos siempre estará en duda su eficacia.

normativos, Barcelona, Marcial Pons, 2005, pp. 84-89. En cuanto al tema de la eficacia y lo simbólico de la misma a la hora de pretender resolver problemas sociales en el contexto colombiano, también existen contemporáneos análisis desarrollados por García Villegas y Boaventura de Sousa en el siguiente sentido: "Los gobiernos en Colombia intentan compensar la incapacidad del Estado para tratar demandas sociales en términos políticos, con una fuerte insistencia en la dimensión jurídica de tales problemas... El déficit de maniobra política de los gobiernos propicia el uso simbólico de los discursos legales. Mientras más limitado es el margen de maniobra política de los gobiernos en Colombia y más incontrolable es la violencia, más inclinados están estos a tratar dichos problemas de manera tal que el énfasis institucional se ponga en la legitimación, la comunicación y el uso simbólico del derecho en la obtención de resultados”. De Sousa Santos, Boaventura y García Villegas, Mauricio, El caleidoscopio de las justicias en Colombia, Bogotá, Siglo XXI Editores, 2001, pp. 73-74.

57 Alexy, Robert, El concepto y la validez del derecho, cit., pp. 172-177.

58 Corte Constitucional de Colombia, Sentencia C-454 de 2006. M. P.: Jaime Córdova Triviño.

59 Corte Constitucional de Colombia, Sentencia C-209 de 2007, M. P.: Manuel José Cepeda Espinosa. 


\section{CONCLUSIONES}

Colombia, como Estado social y democrático de derecho, viene atendiendo precisamente esa evolución histórica, jurídica y política, cuando a la hora de pretender proteger derechos humanos fundamentales de estirpe sexual se trata. Para lo anterior, ha mostrado gran producción legislativa interna al introducir además a su ordenamiento jurídico los acertados enunciados jurídicos internacionales que sobre esa materia se establecen, y desde ese ideal, lograr proteger algo tan natural como lo es la libertad, la integridad y libertad sexual de las personas.

No obstante, la mayoría de esas categóricas prescripciones de protección y paralela prohibición han quedado reducidas al ámbito de su validez formal, por cuanto su incumplimiento al interior de la sociedad es evidente, lo que en consecuencia compromete su eficacia jurídica, que lógicamente se busca desde la creación, y que ha de verse reflejada cuando logra conseguir los efectos que se esperan en el comportamiento humano; esto es, inicialmente la comprensión de que existen unos derechos sexuales protegidos o tutelados por el Estado a través de las normas y, por otra parte, la acertada disuasión de esa prohibición para que efectivamente se respeten bajo la afirmación de una sanción penal.

Desde otro ángulo, las autoridades públicas de manera coetánea a esas creaciones normativas deben implementar también mecanismos idóneos y eficientes para que esa protección pueda ser materialmente válida; es decir, produzca los efectos que se propone el Estado y aquellos intentos no se queden en las meras expectativas. Después de todo, porque pareciera que los agresores con esta tendencia delictiva no alcanzan a ser disuadidos con la norma penal que los puede reprimir, o simplemente la debida obediencia a las mismas no logra instalarse en sus conciencias y mejor deciden incumplir el pacto social propuesto para una vida civilizada. En otras palabras, parece que su conducta humana atiende otro tipo de cláusulas sociales: las del desprecio por la dignidad sexual de su semejante.

Como se pudo observar a lo largo de este artículo, no basta con que el legislador sea amable y consciente de que es necesaria la constante actividad dentro de su función creativa de normas, y con esto hacer creer a la sociedad que aquel dogma que se predica de los derechos sexuales como protegidos en todo momento por el Estado, desde sus prescripciones jurídicas de carácter supraconstitucional, constitucional y legal, como 
también desde aquel desarrollo jurisprudencial, resultan ser suficientes, pues el propósito se ve incumplido como claramente lo siente la sociedad de manera constante, y resulta entonces necesario replantear y analizar otros aspectos relativos a la prevención y protección de los derechos sexuales; pero esto debe partir en sentido estricto desde un marco de acción sociológico y axiológico, que para muchos está en segundo plano, o las contemplan aisladamente, sin considerar, para la fortuna de otros, que precisamente por estar relegadas en ese lugar las aprecian desde tiempos pretéritos, porque están seguros de que observar con objetividad lo que realmente necesita esta sociedad, es decir, sus teorías y los métodos para el conocimiento social, merecen especial atención, para poder encauzar el rescate de los valores que hace mucho entraron en crisis.

Es de considerar que no existe una solución ipso facto del flagelo del delito sexual, debido a que la misma parece distanciarse cada día más a pesar de la producción normativa en esa materia, pues ese encargo no parece disuadir aquella irracionalidad por la que actúa ese agresor, y que por la presunción instalada en la sociedad sobre el conocimiento de la ley, sin duda pareciera saber cuál es el número de normas que previenen o prohíben ese delito; pero es evidente que también infiere que las mismas no lo alcanzan, ni en el lugar, como tampoco respecto de la víctima que elija.

Una creencia en la eficacia de este positivismo merece replantearse en la actualidad, además, porque ha de tenerse en cuenta que el Estado, a través del poder que otorga el derecho, ha hecho lo propio para orientar la conducta humana por el camino del respeto de los derechos sexuales del otro. Lo anterior se ha de traducir, entonces, en que se hace necesario dejar de seguir asignando la responsabilidad de esta ineficacia normativa al mismo Estado, como ente que transversaliza la vida misma, que sin duda existe, sino también apostarle a girar paralelamente en una dirección en la que se involucren otras disciplinas e instituciones a partir de un trabajo riguroso en todas las dimensiones del hombre, para que puedan nutrir profundamente el interior de las familias, lo cual habrá de repercutir en una sociedad que refleja una escala de valores bien estructurada, en donde el respeto, más allá de ser un vocablo de gran connotación axiológica, se convierta en la fórmula más eficaz para mantener siempre vigente el orden social y jurídico.

Se advierte que este enfoque pueda resultar obvio para algunos, situación que a la postre no tiene discusión en este momento, por cuanto les asisten buenas razones para considerarlo así; pero es precisamente por esa 
razón que muchos hombres ya han perdido, es decir, porque lo obvio parece no generar ninguna obligación moral ni mucho menos jurídica, pues cuando asumen esa postura, olvidan que ésa también es una ley de la naturaleza, que a la par de su libertad deben también respetar la libertad del otro. En otras palabras, la racionalidad que se reclama de la humanidad es que en la praxis comprenda que en todo momento y lugar se deben respetar los derechos sexuales ajenos. Asimismo, más que aprender a asimilar el mensaje que las normas jurídicas contiene y desde las cuales también se pretende regular el comportamiento humano, todo hombre debe aprender a identificar de una vez por todas aquella razón colectiva que se llama civilización; por tanto, una mirada seria desde la familia, las instituciones y el Estado frente a todas las dimensiones del hombre, será siempre la mejor alternativa de reconstruir el tejido social. La falta de acceso a estas posibilidades no puede seguir siendo la excusa para seguir creyendo que las normas jurídicas serán la salvación, lo cual, sin duda, seguirá siendo entonces un simple dogma deshumanizado al que se adherirán las generaciones futuras sin reparo alguno.

\section{BIBLIOGRAFÍA}

Aguirre ArAngo, José Pedro, "La interpretación de la Convención Americana sobre Derechos Humanos", Revista de Derechos Humanos, año V, núm. 8, 2007.

Aguirre Roman, Javier Orlando y García OBAndo, Pedro Antonio, Lógica y teoría de la argumentación, Santander, Universidad Industrial de Santander, 2008.

ALEXY, Robert, El concepto y la validez del derecho, Barcelona, Gedisa, 2004.

ALEXY, Robert, Teoría de los derechos fundamentales, Madrid, Centro de Estudios Políticos y Constitucionales, 2002.

AlEXY, Robert, Teoría del discurso y derechos humanos, Bogotá, Universidad Externado de Colombia, 1995.

ANZURES GuRRÍA, José Juan, "La eficacia horizontal de los derechos fundamentales", Cuestiones Constitucionales, núm. 22, 2010.

AtIENZA, Manuel, "Estado de derecho, argumentación e interpretación", Anuario de Filosofia del Derecho, vol. XIV, 1997. 
BeCCARIA, Cesare, De los delitos y las penas, trad. de Francisco Tomás y Valiente, Madrid, Aguilar, 1982.

BoBbio, Norberto, El problema del positivismo jurídico, Buenos Aires, Eudeba, 1965.

BobBio, Norberto, El tercero ausente, Madrid, Cátedra, 1997.

BoBbio, Norberto, Sociedad y Estado en la filosofia política moderna. El modelo iusnaturalista y el modelo hegeliano-marxiano, México, Fondo de Cultura Económica, 1997.

Botero Bernal, Andrés, Diagnóstico de la eficacia del derecho en Colombia y otros ensayos, Medellín, Biogénesis, 2003.

Bozo DE CARMONA, Ana julia, "Karl-Otto Apel: reflexiones sobre la teoría de la verdad y la ética del discurso", Revista de Filosofía, núm. 22, 1995.

Bulygin, Eugenio, Validez y eficacia del derecho, Buenos Aires, Astrea, 2005.

Comte, Augusto, Primeros ensayos, México, Fondo de Cultura Económica, 1942.

De Sousa SAntos, Boaventura y GARCía Villegas, Mauricio, El caleidoscopio de las justicias en Colombia, Bogotá, Siglo XXI Editores, 2001.

FERNÁNDEZ CRUZ, José Ángel, "La interpretación conforme con la Constitución: una aproximación conceptual”, Ius et Praxis, año 22, núm. 2, 2016.

FerRAJOLI, Luigi, Derecho y razón. Teoría del garantismo penal, Madrid, Trotta, 1995.

FIORAVANTI, Maurizio, Los derechos fundamentales. Apuntes de historia de las constituciones, Madrid, Trotta, 2007.

GALÁN JuÁREZ, Mercedes, "La interpretación de los derechos fundamentales por parte del Tribunal Constitucional, una argumentación en términos de razonabilidad", Isegoría, núm. 35, 2006.

GAVIRIA DíAz, Carlos, "Los temas de la constituyente. El Estado social de derecho y la presión política por el cambio", Foro, núm. 7, 2007.

Grández CASTRO, Pedro P., "Argumentación jurídica y derecho constitucional”, en LANDA ARroyo, César (ed.), Derechos fundamentales, Lima, Palestra, 2018. 
GUASTINI, Riccardo, Estudios sobre la interpretación jurídica, trad. de Mariana Gascón y Miguel Carbonell, México, UNAM, Instituto de Investigaciones Jurídicas, 1999.

HART H, L. A., El concepto de derecho, Buenos Aires, Abeledo-Perrot, 2007.

Hobbes, Thomas, Leviatán, trad. de M. Sánchez Sarto, México, Fondo de Cultura Económica, 1980.

Kelsen, Hans, Esencia y valor de la democracia, Buenos Aires, Labor, 1984.

KELSEN, Hans, Teoría pura del derecho, México, UNAM, 2002.

Kelsen, Hans, Validez y eficacia del derecho, Buenos Aires, Astrea, 2005.

LocKE, John, Ensayo y carta sobre la tolerancia, trad. de Carlos Mellizo, Madrid, Alianza, 1999.

LOCKE, John, Segundo tratado sobre el gobierno civil, trad. de Carlos, Mellizo, Madrid, Alianza Edit, 1998.

Massé NARVÁEz, Carlos E. y Rivera HernándeZ, Juan, “La hermenéutica en la interpretación conforme de los derechos humanos en el orden jurídico mexicano", Methaodos. Revista de Ciencias Sociales, vol. 2, núm. 1, 2014.

MendoncA, Daniel y Bulygin, Eugenio, Normas y sistemas normativos, Barcelona, Marcial Pons, 2005.

Mesa de seguimiento al Auto 092 de la Corte Constitucional, Acceso a la Justicia para mujeres víctimas de violencia sexual. Cuarto Informe de Seguimiento al Auto 092 de 2008, Bogotá, Antropos, 2011.

Molina Betancur, Carlos Mario, Derecho constitucional general, Medellín, U de M, 2008.

Molina Betancur, Carlos Mario, Investigación. Bicentenario constitucional, Medellín, U de M, 2010.

PABÓN PARRA, Pedro Alfonso, Delitos sexuales. La sexualidad humana y su protección penal, Bogotá, Doctrina y Ley LTDA, 2005.

RAWLS, John, Liberalismo político, Barcelona, Crítica, 2002.

Reale, Miguel, Teoría tridimensional do direito, São Paolo, Saraiva, 1968.

Ross, Alf, El concepto de validez y otros ensayos, Buenos Aires, Centro Editor de América Latina, 1968. 
VAN DiJK, Teun, A., "Discurso, conocimiento, poder y política. Hacia un análisis crítico epistémico del discurso", Revista de Investigación Linguística, Murcia, núm. 13, 2010.

WALTER, Robert, Validez y eficacia del derecho, Buenos Aires, Astrea, 2005.

Zagrebelsky, Gustavo, El derecho dúctil. El derecho por principios, Madrid, Trotta, 2008.

ZAVAla DE AlBA, Luis Eduardo, "Gobernanza en derechos humanos: hacia una eficacia y eficiencia institucional", Revue québécoise de droit international, Hors-série, mars 2015. 